\title{
Recent Advances in Magnetic Resonance Neurospectroscopy
}

\author{
Yael Rosen and Robert E. Lenkinski \\ Department of Radiology, Beth Israel Deaconess Medical Center, Harvard Medical School, Boston, Massachusetts 02215
}

Summary: Over the past two decades, proton magnetic resonance spectroscopy (proton MRS) of the brain has made the transition from research tool to a clinically useful modality. In this review, we first describe the localization methods currently used in MRS studies of the brain and discuss the technical and practical factors that determine the applicability of the methods to particular clinical studies. We also describe each of the resonances detected by localized solvent-suppressed proton MRS of the brain and discuss the metabolic and biochemical information that can be derived from an analysis of their con- centrations. We discuss spectral quantitation and summarize the reproducibility of both single-voxel and multivoxel methods at 1.5 and 3-4 T. We have selected three clinical neurologic applications in which there has been a consensus as to the diagnostic value of MRS and summarize the information relevant to clinical applications. Finally, we speculate about some of the potential technical developments, either in progress or in the future, that may lead to improvements in the performance of proton MRS. Key Words: Metabolism, MR spectroscopy, Alzheimer's disease, epilepsy, brain tumors, reproducibility.

\section{INTRODUCTION}

Magnetic resonance imaging (MRI) has emerged as the pre-eminent imaging modality for visualizing neurologic diseases in the central nervous system. MRI can be used to produce both high-resolution anatomically-based images and images that reflect a variety of physiological parameters, including blood flow, tissue perfusion, and water mobility as reflected by diffusion indices. Magnetic resonance spectroscopy (MRS) is a complementary technique, providing metabolic information that can easily be integrated with MRI. The current version of MRS has, over the past five decades, evolved from a technique (originally known as nuclear magnetic resonance spectroscopy, or NMR spectroscopy) used in chemistry to determine the structure of molecules to a method with which to probe the metabolism of cells, tissues, intact animals, and humans. ${ }^{1-13}$ Many of these applications involved acquiring ${ }^{31} \mathrm{P}$ spectra to assess the bioenergetics of the cells, tissues, or organs being studied. These studies required using additional radiofrequency (RF) hardware.

Although proton MRS was, and is, used extensively in chemical applications, its use in biological systems (in

Address correspondence and reprint requests to: Robert E. Lenkinski, PhD., Department of Radiology, Beth Israel Deaconess Medical Center, 330 Brookline Avenue, Boston, MA 02215. E-mail: rlenkins@bidmc.harvard.edu. which the concentration of the compounds of interest are $\sim 1-10 \mathrm{mmol} / \mathrm{L}$ ) was hampered by the presence of a large background signal arising from water in the sample, which could have a concentration approaching $90 \mathrm{~mol} / \mathrm{L}$ in protons. In the early days of MRS, this difference in signal amplitudes posed several problems (discussed later in this article), addressed by development of a variety of techniques that either did not excite the background water signal or suppressed it substantially. ${ }^{14-16}$

One of the major motivations for using proton NMR methods is the greater sensitivity of the nucleus $\left({ }^{1} \mathrm{H}\right)$, compared with either ${ }^{31} \mathrm{P}$ or ${ }^{13} \mathrm{C}$. All other factors being equal, the MR sensitivity is proportional to the cube of magnetogyric ratio for each nucleus. This translates into relative sensitivities of $\sim 10: 1$ for protons relative to ${ }^{31} \mathrm{P}$ and $\sim 64: 1$ for protons relative to ${ }^{13} \mathrm{C}$ (at equal concentrations of compounds and isotopic enrichments). Notably, observing nuclei other than proton requires the development of RF coils and other specialized hardware tuned to their specific frequencies, whereas proton MRS uses the same hardware as standard MRI.

The first in vivo localized spectrum of rat brain acquired at $8.5 \mathrm{~T}$ in a vertical bore magnet was published by Behar et al. ${ }^{17}$ in 1983 (FIG. 1). The resonances were assigned with respect to spectra obtained on excised brain tissue and perchloric acid extracts of the brain tissue. Note that the major resonances assigned and the line-width of the lines obtained in vivo were significantly 


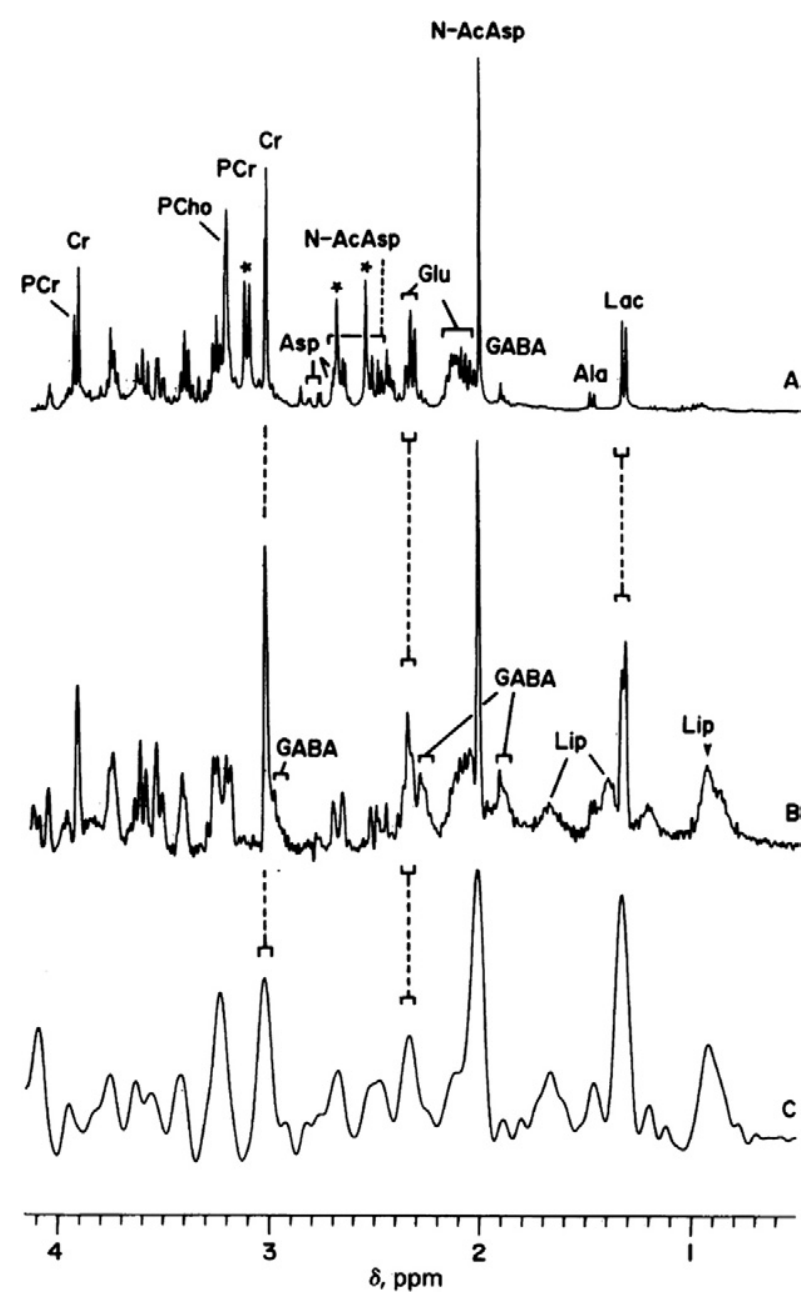

FIG. 1. The high-resolution proton NMR spectrum of rat brain: (A) extract; (B) intact tissue. Spectrum (C) was acquired in vivo on a wide-bore $360-\mathrm{MHz}$ vertical bore system. Abbreviations: Cho, choline; $\mathrm{Cr}$, creatine; lip, lipids; N-AcAsp, $\mathrm{N}$-acetylaspartate; PCho, phosphocholine; PCr, phosphocreatine. Dashed lines indicate matching peaks across spectra. Reproduced with permission from Behar et al., 1983. ${ }^{17}$

broader than those observed from either the intact tissue or extract. Behar et al. ${ }^{17}$ also described the effects of cerebral hypoxia on the spectra (elevations in lactate), indicating the promise that proton MRS has for monitoring the metabolic consequences of various insults on the brain.

The first commercial whole-body 1.5 T MRI scanners (and slightly higher: $2.0 \mathrm{~T}$ ) became available in the early 1980s. In 1985, Bottomley et al. ${ }^{14}$ published the first human in vivo solvent-suppressed proton spectrum of the brain (FIG. 2). Although most of the resonances found in rat brain are also observed, the lines are much broader, indicating that there are contributions from magnetic field inhomogeneities. This report was followed by two other articles showing similar results, one by Luyten and den Hollander ${ }^{18}$ in 1986 and the other by Hanstock et al. ${ }^{19}$ in 1988. In 1989, Frahm's group published a series of papers showing single-voxel MR spectra with much narrower lines, obtained using stimulated echoes ${ }^{15,16,20}$ to localize to different regions of the brain.

These exciting results began the modern era of proton MRS studies of the brain. Since the 1980s, there has been an increasing availability of whole-body MR scanners for use in diagnostic imaging. A large number of these MR scanners operate at magnetic fields of $1.5 \mathrm{~T}$ or higher, similar to the magnetic fields used in the early days of NMR spectroscopy. These scanners can perform localized proton MRS without additional hardware, provided that they have the capability for shimming (i.e., optimizing the field homogeneity).

The development of spatially localized MRS ${ }^{21-24}$ has provided a bridge between metabolism and the anatomic and physiological studies available from MRI. These can now be combined into a single MR examination. In cases where a distinct lesion or lesions are seen on MR, the MRS can provide metabolic profiles that might aid in the characterization of the lesion or lesions and their response to treatment. In cases where MRI reveals no distinct lesions, MRS can provide a noninvasive assessment of the underlying metabolic status of the tissue being studied. This is particularly important in diffuse pathologies, for which MRS may give insights into the patterns of disease evolution and progression.

Several recent reviews of proton MRS studies of the brain are available. ${ }^{25-28}$ Here, we will describe the localization methods currently used in MRS studies of the

(a)

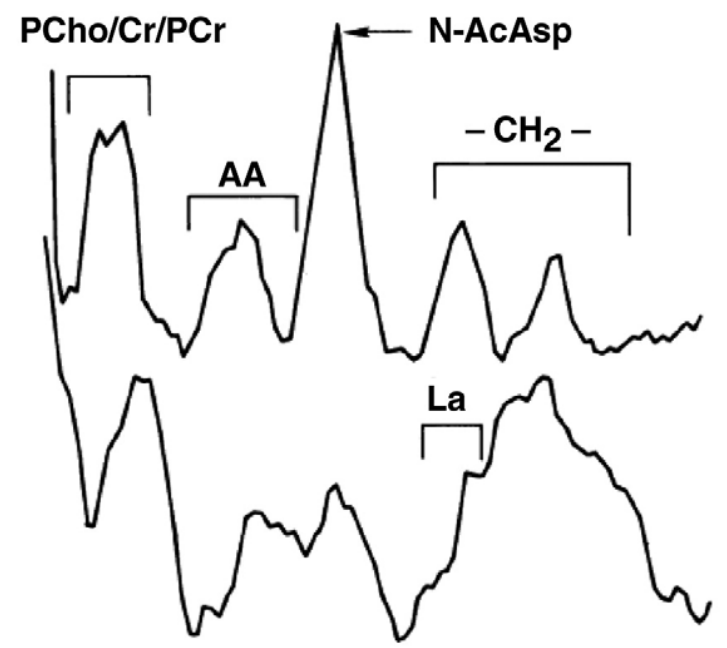

ppm

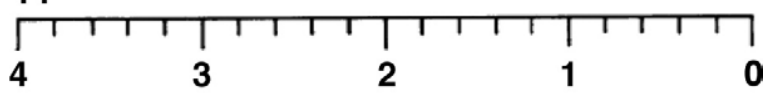

FIG. 2. Typical localized proton spectra from (a) human and (b) dog brain, both taken at $1.5 \mathrm{~T}$ and recorded using a slice-selective sequence (5 $\mathrm{cm}$ depth; $5 \mathrm{~mm}$ slice) using a $3-\mathrm{cm}$ diameter coil. Abbreviations: AA, amino acids (glutamine, glutamate, and GABA); Cr, creatine; La, lactate; N-AcAsp, $N$-acetylaspartate; PCho, phosphoryl-choline; PCr, phosphocreatine. Reproduced with permission from Bottomley et al., 1985. ${ }^{14}$ 
brain and discuss the technical and practical factors that determine the applicability of these methods to particular clinical studies. We will discuss each of the resonances detected by localized solvent-suppressed proton MRS of the brain in terms of the metabolic and biochemical information that can be derived from an analysis of their concentrations. We will then summarize the reproducibility of both single-voxel and multivoxel methods at 1.5 and 3-4 $\mathrm{T}$ and discuss the use of fields higher than 1.5 T. We will review clinical applications where there has been a consensus as to the diagnostic value of MRS. Finally, we will present some of the potential technical developments, either in progress or expected for the future, that may lead to improvements in the performance of MRS.

\section{SPATIAL LOCALIZATION}

Localization can be achieved in MRS by means of using RF gradients, static $B_{0}$ gradients, pulsed spatial gradients, or combinations of these. The technical details of these approaches have been described in detail. ${ }^{21-24}$ The combined RF and gradient methods are similar to those currently used in MRI. As already noted, the challenge in proton spectroscopy of metabolites is that metabolites at millimolar concentrations must be detected in the presence of a background water signal that is $\sim 100$ molar. For this reason, solvent-suppression techniques have been combined with localization schemes to produce spatially localized solvent-suppressed spectra. Both the $T_{1}$ and $T_{2}$ relaxation times of the various proton metabolites are quite long, permitting the use of methods such as spin-echo or stimulated-echo sequences.

For proton MRS of the brain, localization methods that either preserve the magnetization of only those protons being sampled and destroy the coherence of all of the unwanted spins, or pulse sequences wherein only the spins from the desirable locations are excited, or combinations of these two approaches, have found common use. The unwanted magnetization arises from several sources: the background water signal and the strong lipid signal arising from fat in the scalp. Regions with high magnetic susceptibility boundaries should be avoided in the excitation schemes.

Suppression of the water signal is usually accomplished by a $90^{\circ}$ frequency selective excitation of the water followed by dephasing gradients. This process destroys all the magnetization components of the water (both the Z-magnetization and the $X Y$ magnetization). The efficiency of suppression depends on a number of factors, including the $B_{1}$ homogeneity of the $90^{\circ}$ frequency selective excitation of the water (i.e., is this pulse a $90^{\circ}$ pulse everywhere within the brain?) and the magnetic field homogeneity across the volume being sampled.
The two most commonly used localization methods, stimulated echo acquisition mode (STEAM) and point resolved spectroscopy (PRESS), select an orthorhombic volume in space by applying three sequential selective $\mathrm{RF}$ pulses in the presence of orthogonal slice-selective gradients. The STEAM sequence ${ }^{15,16}$ and PRESS ${ }^{14}$ method can be implemented as single-voxel (i.e., sampling only one region of tissue) or multivoxel methods (selecting a larger orthorhombic volume combined with Fourier phase-encoding methods to produce both twodimensional and three-dimensional chemical shift imaging data-2D-CSI and 3D-CSI). ${ }^{21-24}$ Because both STEAM and PRESS excite the spins within the orthorhombic volume, these are examples of methods in which only those protons being sampled are excited and the other spins are either not excited or are destroyed. The advantages of using either of these two spatial preselection methods are that the signal from lipids arising from the scalp is minimized and the volume over which the $\mathrm{B}_{0}$ field is adjusted can be restricted to avoid air-tissue boundaries, with their potential large variations in the magnetic susceptibility.

For reasons associated with instrument performance (e.g., residual eddy current effects), many of the early reports of proton MRS used echo delays of 135 or 270 $\mathrm{ms}$. The choice of 135 or $270 \mathrm{~ms}$ is made to refocus the doublet resonance of the methyl resonance of lactate. As instrumental performance has improved, the greater emphasis has been placed on acquiring proton spectra at shorter echo times (TE) of 20-60 ms. One advantage of these shorter delays is the ability to detect resonances from coupled spin systems (e.g., glutamate, glutamine, myo-inositol) whose apparent $\mathrm{T}_{2}$ 's are too short to permit detection at longer echo delays.

The STEAM sequence originally provided more precise localization because the slice profiles of the $90^{\circ}$ pulses were sharper than those achieved by conventional $180^{\circ}$ refocusing pulses..$^{29,30}$ The precision of spatial localization was improved in PRESS in two ways. First, the development of so-called digitally crafted or designer RF pulses has improved the quality of the slice profiles of the $180^{\circ}$ pulses. $^{31-39}$ In addition, slice profiles have been improved through the use of a very selective spatial saturation pulse that can be applied at the six edges of the orthorhombus defined by either STEAM or PRESS spatial preselection. ${ }^{40}$

In spite of these improvements, STEAM and PRESS may not be ideal methods for performing multivoxel studies of the brain. The requirement of selecting an orthorhombic volume means that major regions of the brain will not fit within this volume. These deficiencies have led investigators to use a variety of alternative methods to perform whole-brain MRS. One approach is to use spatial presaturation methods to destroy the magnetization from tissues close to air-tissue boundaries, 
where there may be large variations in the magnetic susceptibility. This method of spatial presaturation is often referred to as outer volume suppression (OVS). Other approaches that excite the full slice have used software techniques to remove spectral distortions arising from lipid resonances in the scalp. Both types of approach permit acquiring MRS spectra from regions of the brain that lie outside the orthorhombic volume defined using PRESS preselection.

Another potential problem with PRESS 3D-CSI methods is that the total acquisition time for 3D-CSI sequences can become quite long, because localization in all three dimensions is achieved by phase-encoding. To make scan times shorter and more manageable in clinical applications, most implementations of PRESS 3D-CSI methods use eight slice-encodes, which can result in relatively poor slice profiles. ${ }^{21}$

A number of recent advances in both pulse sequence design and multireceiver (phased-array) RF coils can reduce acquisition times. For example, the spatial presaturation methods (OVS) can be combined with sliceinterleaved spin-echo sequences to provide multislice CSI acquisitions instead of the 3D-CSI methods based on PRESS selection. These multislice approaches have both shorter scan times (several interleaved slices per repetition time [TR] period) and improved slice profiles, compared with PRESS 3D-CSI. Also, these multislice methods can use dynamic shimming on each slice to improve the homogeneity relative to the PRESS-based sequences. Another approach is to use Hadamard encoding in the slice direction to improve slice profiles. ${ }^{41,42}$ The advantages and disadvantages of a variety of different approaches to whole-brain CSI have been discussed in detail by Barker and $\operatorname{Lin}^{26}$ and Keevil. ${ }^{24}$ A comparison of the performance of many of these CSI methods has been provided by Pohmann et al. ${ }^{43}$

Barker and $\mathrm{Lin}^{26}$ have an excellent discussion of methods that use multireceiver arrays (e.g., an eightchannel head array) to accelerate CSI acquisitions, similar to the methods used in parallel imaging. An added complication is that, although there have been descriptions of algorithms ${ }^{44,45}$ used in combining CSI spectra obtained from each individual coil element, few of these are routinely available on commercial whole-body clinical scanners. This situation is in contrast to multicoil MR imaging and parallel imaging, in which this combination (or acceleration, or both) is performed routinely. ${ }^{46}$ In spite of the large number of choices that are available to investigators interested in 3D-CSI studies of the brain and their clear potential advantages over the PRESS family of methods, most whole-brain studies in the literature use PRESS-3D-CSI, probably because it is routinely available on most commercial MRS packages on whole-body scanners.

\section{COMPOUNDS DETECTED BY MRS IN THE HUMAN BRAIN}

Examples of proton MR spectra obtained from gray matter and white matter acquired using the PRESS sequence at $1.5 \mathrm{~T}$ with a TE of $35 \mathrm{~ms}$ are shown in Figure 3. The most prominent resonances are labeled on these spectra. We will discuss each of these resonances (moving in turn from low to high parts-per-million values [ppm]). The biochemical basis for interpreting these spectra has been discussed in detail by Ross et al. ${ }^{28}$ and Ross and Bluml. ${ }^{47} \mathrm{We}$ will briefly review these here.
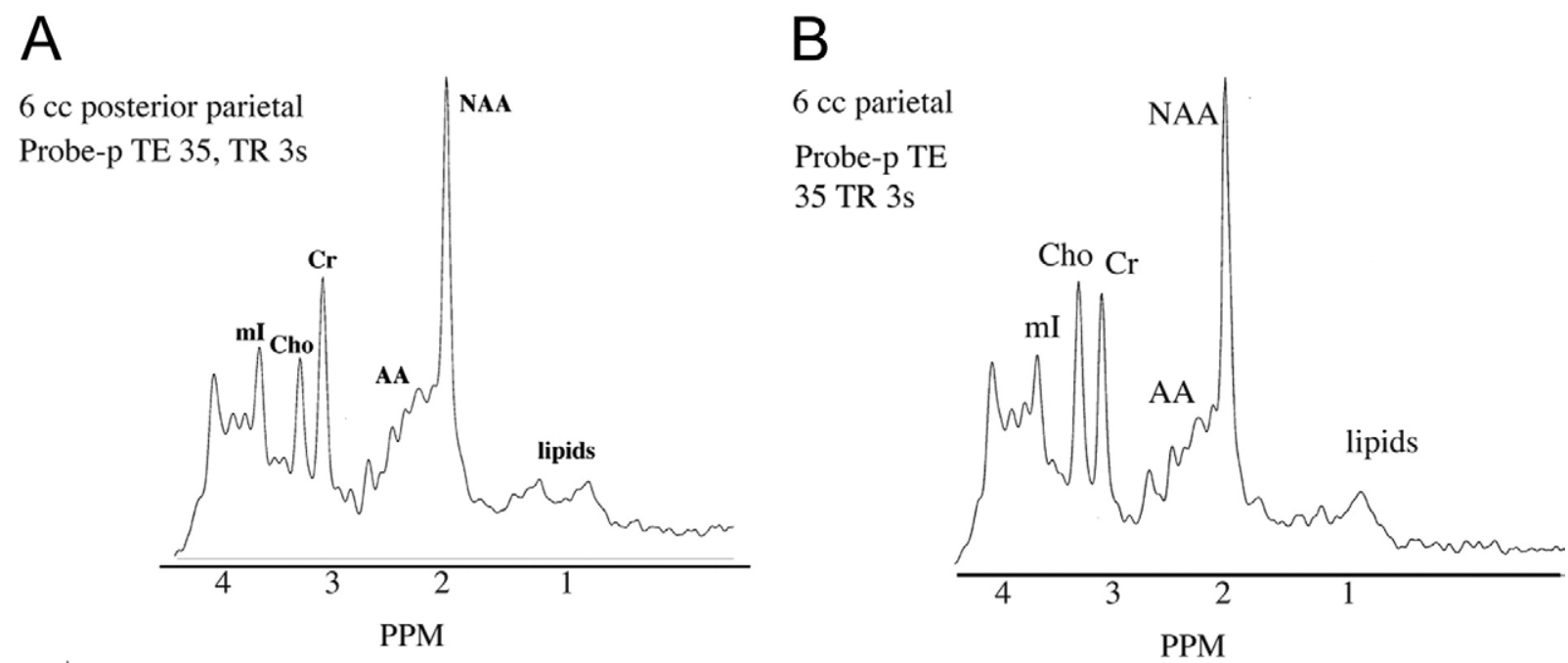

FIG. 3. Short-TE spectra of gray and white matter. Representative MR spectra acquired at $1.5 \mathrm{~T}$ at an echo delay of $35 \mathrm{~ms}$ using the PRESS sequence from (A) gray matter and (B) white matter. Abbreviations: AA, amino acids (glutamine, glutamate, and GABA); Cho, choline; Cr, creatine; ml, myo-inositol; NAA, $N$-acetylaspartate. 


\section{Lipid and lactate}

Lactate is a doublet at $1.3 \mathrm{ppm}$. It is the end product of glycolysis. In general, lactate can become elevated in the brain in two ways. First, lactate will be produced if the tissue becomes ischemic. Second, it has been shown that lactate can become elevated if there are activated inflammatory cells present. Activated macrophages have been shown to produce high levels of lactate. ${ }^{48}$

Lipids ( 0.9 and $1.3 \mathrm{ppm}$ ) can become elevated in some pathologic states. In general, most studies have avoided making any interpretations based on these resonances, because it is often unclear whether these peaks arise from out-of-voxel contamination (i.e., poor spatial localization).

\section{$\mathrm{N}$-Acetylaspartate}

The isolation and identification of $\mathrm{N}$-acetylaspartate (NAA) $(2.0 \mathrm{ppm})$ in the brain of cats was reported by Tallan et al. ${ }^{49}$ in 1956. Soon after the detection of NAA in proton MRS, Birken and Oldendorf ${ }^{50}$ reviewed the literature regarding the role of NAA in brain biochemistry. In spite of more than 40 years of investigation, the role of NAA in the brain remains somewhat unclear. Simmons et al. ${ }^{51}$ reported that NAA was found exclusively in neurons. This and many other observations have led many to conclude that NAA is a neuronal marker. This conclusion was questioned by Martin et al. ${ }^{52}$ who reported MR spectra with little or no NAA in a three year-old patient with developmental deficits. This report was followed by several letters to the editor discussing the role of NAA as a neuronal marker. ${ }^{53-55}$

There are approximately equal concentrations of NAA in white and gray matter, which raises the issue of whether NAA is a marker of axonal integrity as well. The utility of NAA as an axonal marker is supported by the loss of NAA in many white matter diseases, including leukodystrophies, multiple sclerosis (MS), and hypoxic encephalopathy. Because MS is thought to be a disease that affects axons, the level of NAA has been used to monitor axonal viability in white matter lesions of MS and in surrounding normal-appearing white matter.

Several groups have suggested that NAA is a cerebral osmolyte. $^{28,56-59}$ This proposed role for NAA implies that NAA changes might be reversible, an observation that has been made in several human studies including MS, acquired immunodeficiency syndrome (AIDS), and temporal lobe epilepsy. ${ }^{26}$

\section{Amino acids}

Glutamine (Glu), glutamate (Gln), and GABA are labeled as amino acids (AA) (2.1-2.4 ppm) in the spectra (FIG. 3). The determination of the individual concentrations of these compounds using ${ }^{1} \mathrm{H}$ MRS is hampered by the complex spectral appearance of Glu/Gln (Glx) due to J-coupling. Other metabolites also contribute to the signal at the chemical shift of Glu/Gln, which makes the accurate and precise determination of their concentrations difficult at $1.5 \mathrm{~T}$. There are, however, indications that the use of higher field strengths can improve the quantitation of these compounds. ${ }^{60-64}$

Glutamate is of interest because it is the most abundant neurotransmitter in the brain, and Shulman's group ${ }^{65,66}$ estimated that the cycling between Gln and Glu accounts for more than $80 \%$ of cerebral glucose consumption. Recently, it has been shown that Glu is elevated in MS patients, in the MS lesions as well as in normally appearing white matter. ${ }^{67}$ Elevations in Gln have been reported in patients with hepatic encephalopathy ${ }^{68-70}$ and Reye's syndrome. ${ }^{71}$ Recently, Moore et al. ${ }^{72}$ showed that the administration of topiramate increased brain Gln levels (detected at $4 \mathrm{~T}$ ). This was interpreted as a consequence of topiramate positively modulating $\mathrm{GABA}_{\mathrm{A}}$ receptors. This finding is of interest because of the possible role for topiramate (not for) in the treatment of epilepsy, migraine headache, bipolar disorder, eating disorders, and alcohol dependence.

The detection and quantitation of GABA is of interest because there are a variety of drugs on the market that can, in principle, modulate GABA levels in the brain. Several groups have actively pursued the measurement of GABA, both at rest and under the modulation of a variety of agents. ${ }^{70,73-82}$ Note that all of these studies have been performed either at fields higher than $1.5 \mathrm{~T}$ or with special spectral editing sequences, or a combination of both.

\section{Creatine}

The neurobiochemistry of creatine $(\mathrm{Cr})(3.0 \mathrm{ppm})$ has been discussed by Ross and Bluml. ${ }^{47,83}$ This resonance is made up of at least two compounds, $\mathrm{Cr}$ and phosphocreatine, that are in rapid chemical and enzymatic exchange. The total concentration of this compound is estimated to be $8.6 \mathrm{mmol} / \mathrm{L}$ in human brain. Many studies use the level of the $\mathrm{Cr}$ peak as an internal standard, because the levels of $\mathrm{Cr}$ are thought to be relatively constant across the brain and do not change in most pathologies. Caution is advised, however: in cases where there is tissue destruction, the level of $\mathrm{Cr}$ might fall. Also, there has been at least one report wherein a new human inborn error of Cr biosynthesis was manifested as an absence of cerebral $\mathrm{Cr}$ from the proton spectrum, a deficiency that was corrected by dietary administration of $\mathrm{Cr}^{84}$

\section{Choline}

The biochemistry of the choline-containing compounds has been reviewed by Miller. ${ }^{85}$ The choline (Cho) (3.2 ppm) resonance arises from the tetramethyl amine head group in soluble compounds such as Cho, phosphocholine, glycerophosphocholine, and betaine. From Figure 3, it is clear that there are different levels of Cho in gray and white matter. Ross and Bluml ${ }^{47}$ have reported that the concentration of $\mathrm{Cho}$ is $\sim 1.6 \mathrm{mmol} / \mathrm{L}$ in 
white matter. There is also compelling evidence that glial cells have a high concentration of Cho. ${ }^{86-88}$

During active myelin breakdown, there is thought to be a release of phospholipids, leading to an increase of the Cho peak. ${ }^{89}$ Increases in Cho due to inflammation have also been reported. ${ }^{90,91}$ These two observations may cause some overlap in interpreting results in lesions, such as tumefactive MS, ${ }^{92-95}$ that may have both inflammation and demyelination present.

Elevations in the Cho resonance in brain lesions have also been accepted as a sign of malignancy, ${ }^{96-103}$ which may add an additional level of nonspecificity to any interpretations made on the basis of this peak alone.

\section{Myo-inositol}

Myo-inositol (mI) (3.6 ppm) is a simple sugar that has a deceptively simple spectrum at $1.5 \mathrm{~T}$. In the brain, $\mathrm{mI}$ is synthesized primarily in glial cells and cannot cross the blood-brain barrier. ${ }^{104,105}$ Myo-inositol is therefore considered to be a glial marker, and an increase in $\mathrm{mI}$ content is believed to represent glial proliferation or an increase in glial cell size. Because both processes may occur in brain inflammation, an increase in $\mathrm{mI}$ may be a surrogate marker for inflammation in the brain. Myoinositol has been suggested as a cerebral osmolyte since $1990 .{ }^{106}$ Like Cho, mI has also been labeled as a breakdown product of myelin. ${ }^{107}$

\section{QUANTITATION}

Quantitation has been reviewed recently by Jansen et al. ${ }^{108}$ There is still an ongoing debate on the merits concerning the relative versus absolute quantitation of the compounds detected by proton MRS in the brain.

One view is that only the determination of absolute concentrations is acceptable. This is based on the observation that the levels of all of the metabolites, including $\mathrm{Cr}$, can change in brain pathologies. The calculation of absolute concentrations requires correction for many factors, including compartmentalization of compounds, correction for $T_{1}$ and $T_{2}$ relaxation effects, correction for excitation and reception profiles, determination of the actual rather than the prescribed volume sampled in both single-voxel and multivoxel studies, and referencing the results to a known internal or external standard. Several different approaches have been suggested for absolute quantitation. ${ }^{109-116}$ Most of these approaches make attempts to obtain estimates of the concentration of water and its compartmentalization in the brain volume (voxel) being sampled by spectroscopy. A common method involves fitting the $T_{2}$ decay curve of water in the voxel to several exponential decay curves in order to obtain estimates of the water in CSF and the concentration of water in various compartments of brain tissue in the volume being sampled. By referencing the relative area of the brain metabolite to the tissue water, one can, in principle, obtain estimates of its absolute concentration.

Critics of absolute quantification suggest that it may be impossible to correct for all of these factors, particularly in the presence of pathologic changes, without making potentially flawed assumptions. They therefore prefer to report relative concentrations, usually expressed as metabolite-to-Cr ratios. The potential flaw in this approach is that if the level of $\mathrm{Cr}$ is affected by the disease process, the use of the ratios themselves might be misleading.

The common step in either of these quantitation approaches is fitting the acquired spectra, to determine the area under each resonance. A number of approaches have been suggested for performing this step in the brain, and these various approaches applied to processing and fitting spectral data were recently reviewed in a series of articles devoted to spectral quantitation. ${ }^{117-120}$

One tool that appears to be gaining wide acceptance is LC-Model. We routinely use LC-Model to automatically fit CSI data sets obtained from the brain, using a version similar to that described by McLean et al. ${ }^{121,122}$ An example of the results of a fit of LC-Model to a brain spectrum obtained at $3 \mathrm{~T}$ from a normal volunteer is shown in Figure 4. Note that the output of LC-Model includes both relative and absolute concentrations of the various compounds detected, as well as their standard deviations.

\section{REPRODUCIBILITY OF MRS STUDIES OF NORMAL CONTROLS}

The first report of a multisite trial of an automated, standardized, single-voxel, short TE (35 ms), PRESS brain MRS study performed at $1.5 \mathrm{~T}$ appeared in $1994{ }^{123}$ A total of 131 spectra of 84 subjects at 11 sites gave ratios of NAA/Cr of $1.51 \pm 0.10$; Cho/Cr of $0.87 \pm$ 0.10 and $\mathrm{mI} / \mathrm{Cr}$ of $0.66 \pm 0.07$. These spectra were acquired from a $2 \times 2 \times 2-\mathrm{cm}$ voxel located in the right parietal region.

More recently, Venkatraman et al. ${ }^{124}$ compared the precision (reproducibility) and variability of singlevoxel PRESS data collected from the anterior cingulate and hippocampus at $4.0 \mathrm{~T}$ with reproducibility (single subject scanned multiple times) $)^{125-133}$ and variability studies (many subjects scanned at least once) ${ }^{109,115,120,128-130,134-144}$ from the literature (many different regions of the brain). The motivation for the Venkatraman study was the review of Steen et al., ${ }^{145}$ who found an average coefficient of variation $(\mathrm{CV}, \%=$ $\mathrm{SD} /$ mean $\times 100)$ for NAA by Steen et al. ${ }^{145}$ in the frontal lobe in healthy controls of $13.7 \%$ at $1.5 \mathrm{~T}$ (from 16 published studies). Venkatraman et al. ${ }^{124}$ postulated that this $\mathrm{CV}$ could be reduced by acquiring the data at a higher field (i.e., $4 \mathrm{~T}$ ). 
NM290803 NM290803 08/29/2003 TR/TE $=2000 / 38 \mathrm{TG}=161 \mathrm{R} 1=11 \mathrm{R} 2=30 \mathrm{VOI}=2.25 \mathrm{~mL}$ Calib= 0.08 Data of: Center for Advanced Imaging. Beth Israel Deaconess Medical Center

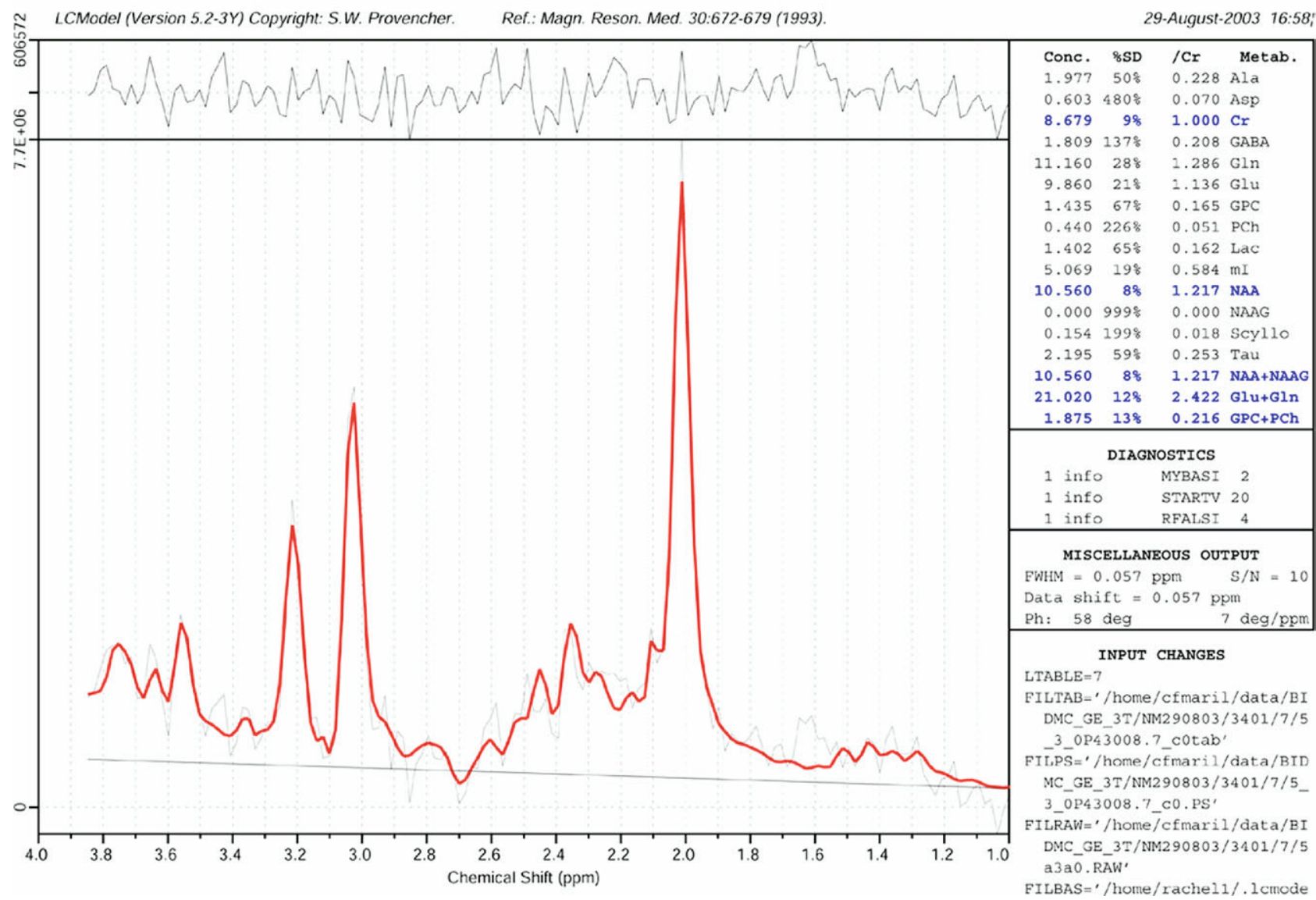

FIG. 4. LC-Model output. Sample output of LC-Model fitting of a spectrum obtained at $3 T$ from a normal volunteer using PRESS at TE of $35 \mathrm{~ms}$. Note that LC-model provides both the relative and absolute concentrations of the compounds listed on the right.

Their review of the literature showed that there were little differences in the CVs of the major peaks (NAA, Cr and Cho) observed between STEAM $(\mathrm{CV}=6.0 \%)$ and PRESS $(\mathrm{CV}=7.4 \%)$ acquisitions. The average $\mathrm{CV}$ s for the variability studies (e.g., NAA $=10.5 \%$ ) were higher on average than those reported for the precision studies $(\mathrm{NAA}=5.4 \%)$, indicating that the biological variability might be important. The location of the single-voxel was important. For example, spectra obtained from the hippocampus showed the highest CVs $(>12 \%$ on average).

The results reported by Venkatraman et al. ${ }^{124}$ in their precision study also showed higher CVs in the hippocampus $(13.9 \%)$ than in the anterior cingulate $(9.2 \%)$ for the major metabolites. For mI, Glu, and Glu+Gln (Glx), the average CVs were also appreciably higher in the hippocampus $(21.2 \%)$ than in the anterior cingulate (15.3\%). These authors also found higher average CVs in their variability study, compared with the precision study. The factors influencing these CVs were discussed in detail. We note that the CVs of the major metabolites at $4 \mathrm{~T}$ were not significantly lower than those reported at $1.5 \mathrm{~T}$; however, the study at $4 \mathrm{~T}$ used the shortest acqui- sition time (4 minutes) and their volume of interest was among the smallest of the studies used in the comparisons. Both of these factors will influence the values of the CVs obtained for all of the metabolites.

Several studies were not included in the review by Venkatraman et al. ${ }^{124}$ For example, Michael et al. ${ }^{146}$ reported similar standard deviations to those found by Venkatraman et al. ${ }^{124}$ for Glx measurements obtained at $1.5 \mathrm{~T}$ using short TE STEAM in the left prefrontal cortex. Hammen et al. ${ }^{147}$ reported CVs ranging from $8.8 \%$ for NAA to $19.4 \%$ for Glu+Gln in the hippocampus, acquired using short TE PRESS at $1.5 \mathrm{~T}$. Wellard et al. ${ }^{148}$ investigated the physiological variability in single-voxel short TE PRESS spectra at $3 \mathrm{~T}$ in the temporal and frontal lobes. They found the largest variability in measurements of Glu-Gln (29\%) and in $\mathrm{ml}(28 \%)$. The variability in measurements of the major metabolites were similar to those described above. They concluded that the largest source of variability was caused by physiological variability rather than by instrumental factors.

Soreni et al. ${ }^{149}$ examined the intraindividual variability in the striatum at $3 \mathrm{~T}$ using a short TE PRESS sequence. They 
found, in accord with previous studies, ${ }^{150-152}$ that there was an effect of laterality on the MR spectra. This laterality was interpreted in terms of voxel repositioning effects, rather than biological differences. ${ }^{151}$ These authors found a higher level of NAA (but not $\mathrm{Cr}$ ) in the afternoon than in the morning, within subjects. Two different hypotheses were offered for these differences. The first possible explanation is based on the fact that there is a known circadian variation of blood glucose levels. Also, there is coupling of NAA synthesis to glucose metabolism, leading to the possibility that the changes in NAA levels reflect indirectly the circadian variations in glucose. The second explanation is based on circadian variations in hydration. Because NAA has been shown to be involved in osmotic regulation, it is possible that alterations in brain hydration could lead to changes in NAA levels.

There have also been several reports on the reproducibility and reliability of CSI methods for brain studies. ${ }^{127,153-164}$ In general, the CVs of the metabolites were higher in the CSI studies than the single-voxel acquisitions. For example, Marshall et al. ${ }^{155}$ reported CVs for NAA of $\sim 20 \%$ at a TE of $25 \mathrm{~ms}$ at $1.5 \mathrm{~T}$ and $\sim 12 \%$ for a TE of $145 \mathrm{~ms}$. There was also a wide range of CVs for NAA reported across different regions of the brain. Maton et al. ${ }^{159}$ reported $14-20 \%$ changes in NAA, Cho and $\mathrm{Cr}$ on long TE PRESS studies of the hippocampus at 1.5 T. Recently, Inglese et al. ${ }^{153}$ found the lowest CV for NAA at a TE of $288 \mathrm{~ms}$ regardless of what coil (singlechannel quadrature head coil versus eight-channel phased array) or field was used (1.5 T versus $3 \mathrm{~T})$. This finding complicates planning studies, because resonances such as mI, Gln, GABA, and Glu cannot be detected at long TEs. In fact, Srinivasan et al. ${ }^{154}$ have reported significant improvements in the measurement of $\mathrm{mI}$ at 3.0 versus $1.5 \mathrm{~T}$ at short TEs.

The statistical variabilities of the metabolite levels establish important benchmarks for comparing results between different patient groups, different field strengths, and different institutions. The potential effects of biological variation add another level of complexity to these kinds of comparisons. Finally, it is clear that there are a number of technical issues that still need to be addressed in a standardized way in order to improve the consistency of CSI results across patients and institutions.

\section{IS PROTON MRS OF HUMAN BRAIN BETTER AT FIELDS HIGHER THAN 1.5 T?}

MRS applications have always been drivers of moving to higher fields (for a review of high-field MRI and MRS, see Lenkinski $2006^{165}$ ). This is based on experience with high-resolution NMR, for which the signal-to-noise ratio has improved with increasing field strength. By convention, in NMR and MRS, the signal-to-noise ratio is de- fined as peak amplitude divided by the root mean square of the noise level. It is well known that for biological samples in MRI the signal-to-noise ratio should scale linearly with the field. This is true as well for localized MRS, provided that the line-width of the resonance being detected does not increase with increasing field strength.

At present, there appears to be some confusion in the literature regarding the advantages of high field for proton MRS studies of human brain. The Minnesota group has shown excellent spectra from human brain at $7 \mathrm{~T} .^{166}$ In these spectra, however, the line-width of the methyl resonance of $\mathrm{Cr}$ was found to be $9.5 \mathrm{~Hz}$, compared with $5.5 \mathrm{~Hz}$ at $4 \mathrm{~T}^{166}$ As was the case in MR imaging, the line-widths at the higher fields have a significant contribution from diffusion of the metabolites through microscopic susceptibility gradients. This effect has been called dynamic susceptibility broadening, and it cannot be corrected by external shimming. In spite of the contribution of this dynamic susceptibility broadening to the line-widths of resonances at higher fields, shimming at the higher field is still crucial to the acquisition of highquality spectra.

Several investigators have shown that the signal-tonoise ratio gains at $3 \mathrm{~T}$ and $4 \mathrm{~T}$ are relatively modest compared with those predicted by theory. Bartha et al. ${ }^{128}$ acquired multiple STEAM spectra $(\mathrm{TE}=20 \mathrm{~ms}$, volume $=8 \mathrm{~cm}^{3}$ ) in a single individual at $1.5 \mathrm{~T}$ and $4 \mathrm{~T}$, to compare the precision of metabolite quantification using automated software that incorporated field strength-specific prior knowledge. At $4 \mathrm{~T}$, the signal-tonoise ratio based on peak height increased $\sim 80 \%$, and the line-widths increased $\sim 50 \%$. This signal-to-noise ratio increase improved the precision of quantification of metabolites by $\sim 40 \%$.

Barker et al. ${ }^{167}$ compared single-voxel proton spectra of the human brain recorded in five subjects at both 1.5 $\mathrm{T}$ and 3.0 T, using the STEAM pulse sequence and data acquisition parameters that were closely matched between the two field strengths. Spectra recorded in the white matter of the centrum semiovale and in phantoms were compared in terms of resolution and signal-to-noise ratio. The values of $T_{2}$ were estimated at both field strengths. Spectra at $3 \mathrm{~T}$ demonstrated only a $20 \% \mathrm{im}-$ provement in sensitivity, compared to $1.5 \mathrm{~T}$ at short echo times $(\mathrm{TE}=20 \mathrm{~ms})$. Although spectra in phantoms demonstrated significantly improved resolution at $3 \mathrm{~T}$, compared with $1.5 \mathrm{~T}$, the in vivo spectra showed almost a twofold increase in line-width at $3 \mathrm{~T}$.

Based on a comparison of multivoxel studies at 1.5 and $3 \mathrm{~T}$, Gonen et al. ${ }^{168}$ showed that the expected gains in signal-to-noise ratio (23-46\%) and spectral resolution were less than theoretically predicted; however, even these modest improvements led to more reliable peakarea estimations and an ${ }^{1} \mathrm{H}-\mathrm{MRS}$ acquisition $\sim 50 \%$ shorter at 3.0 versus $1.5 \mathrm{~T}$. Li et al. ${ }^{169}$ have shown why 
the gains at higher field are not as large as expected. Their explanation deals with the contribution of dynamic susceptibility broadening to the line-widths. In principle, decreasing the voxel size in the spectral acquisition may reduce the increase in line-width. This has been experimentally verified by $\mathrm{Li}$ et al. ${ }^{169}$ Because the signal-tonoise ratio (as determined by the peak height) scales inversely with the line-width for a given peak area, these authors have pointed out that the signal-to-noise ratio decreases much less than expected as the voxel size is decreased. Thus, for higher field proton MRS, optimal signal-to-noise ratio gains may be achievable at smaller voxel sizes than are currently being used at $1.5 \mathrm{~T}$.

As pointed out in the previous section, Srinivasan et al. ${ }^{154}$ found that the reliability of determining the concentration of $\mathrm{mI}$ was significantly better at $3.0 \mathrm{~T}$ than at $1.5 \mathrm{~T}$. They reported a relative improvement in signalto-noise ratio of 1.8 for $\mathrm{mI}$ at $3.0 \mathrm{~T}$, compared with an improvement of 1.4 for the other metabolites. (Note that these studies were necessarily performed at short TE.)

Barker and $\operatorname{Lin}^{26}$ have provided an excellent discussion of the effects of dynamic susceptibility broadening on the apparent $T_{2}$ of a given resonance. They point out that, although the real $T_{2}$ of a resonance such as that of NAA (measured with a CPMG sequence) does not change with field strength, the $\mathrm{T}_{2}$ determined with a single spin echo becomes much shorter at higher fields, due to the effects of dynamic susceptibility broadening. Thus, Barker and $\mathrm{Lin}^{26}$ recommend that MRS studies at higher field be performed at short echo delay. This short TE, however, will result in the detection of broad resonances in the baseline arising from so called macromolecular species. As a result, fitting programs such as LC-Model have been modified to include these resonances in spectral fitting approaches. Alternatively, macromolecular nulling approaches can be incorporated into the acquisition sequences to improve the baseline.

\section{CLINICAL APPLICATIONS}

In their recent review, Ross et al. ${ }^{28}$ list and review the 12 most common uses for neurospectroscopy. We will focus on three of these areas (for more comprehensive reviews, see Gillard et al., ${ }^{25}$ Lentz et al., ${ }^{27}$ and Ross et $\mathrm{al}^{28}$ ), in which there have been replicable results reported from several institutions and there is a consensus that proton MRS has diagnostic value: Alzheimer's disease ( $\mathrm{AD})$, epilepsy, and adult brain tumors.

\section{Alzheimer's disease}

We have previously reviewed the application of proton MRS to study a variety of white matter diseases. ${ }^{170}$ Here we summarize applications of proton MRS to AD, which have been reviewed recently by Mandal ${ }^{171}$ and by Soher et al. ${ }^{172}$ Historically, the definitive diagnosis of AD was
TABLE 1. The spectral patterns that distinguish different dementias

\begin{tabular}{lcc}
\hline Metabolite Ratio & Difference Between Groups & $P$-value \\
\hline NAA/Cr & DLB $>$ AD & $<0.001$ \\
& DLB $>$ FTLD & 0.009 \\
Cho/Cr & AD $>$ VaD & 0.02 \\
$\mathrm{mI} / \mathrm{Cr}$ & FTLD $>$ VaD & 0.002 \\
& FTLD $>$ DLB & 0.02 \\
\hline
\end{tabular}

Adapted from Kantarci et al. ${ }^{174}$

Abbreviations: AD, Alzheimer's disease; Cho, choline; $\mathrm{Cr}$, creatine; DLB, dementia with Lewy bodies; FTLD, frontotemporal lobar dementia; mI, myo-inositol; NAA, $N$-acetylaspartate; VaD, vascular dementia.

made by pathologists at autopsy. MRI studies have attempted to show specific patterns of cerebral atrophy (primarily in the temporal lobe) in patients with a clinical diagnosis of AD. In 1993, Miller et al. ${ }^{173}$ showed clear changes in MRS results in patients with AD. Their report has been followed by a host of other articles that have shown reproducible patterns of decreased NAA and increased $\mathrm{mI}$ in the occipital, temporal, parietal, and frontal regions of patients with $\mathrm{AD}$, even at the early stages of the disease. ${ }^{171,172}$

These patterns of spectral alterations can be used to differentiate patients with suspected $\mathrm{AD}$ from normal elderly controls, as well as patients with other kinds of dementias. ${ }^{174}$ These patterns, adapted from Kantarci et al., ${ }^{174}$ are summarized in TABLE 1 . These data were collected using a short echo PRESS sequence from a voxel positioned in the posterior cingulate gyri and inferior precunei. Note, that the discriminations were made on the basis of comparisons made pairwise using singlepeak ratios. Further improvements might be made by trying approaches such as linear discriminant analysis to separate the groups.

MRS has also been shown to be capable of diagnosing mild cognitive impairment (MCI), which has been recognized as a condition that can precede the development of $\mathrm{AD}$. Moreover, MRS is capable of predicting which subjects with MCI will develop AD. ${ }^{175-178}$ This finding is of particular interest, given the increasing number of clinical trials aimed at evaluating the efficacy of different drugs in treating AD. The availability of a noninvasive method to monitor treatment response would be of enormous benefit in such studies.

\section{Epilepsy}

The application of proton MRS to study temporal lobe epilepsy was recently reviewed by Ross and Sachdev ${ }^{179}$ and by Briellmann et al. ${ }^{180}$ The report by Connelly et al. ${ }^{181}$ in 1994 showed a mean reduction of $22 \%$ in the NAA signal, with a $15 \%$ increase in the $\mathrm{Cr}$ signal and a $25 \%$ increase in the Cho signal in the temporal lobes ipsilateral to the seizure focus, compared with normal 
controls. On the basis of the NAA/Cho + Cr ratio, correct lateralization was achieved in 15/18 cases. They concluded that proton MRS provided useful information in the preoperative investigation of patients with temporal lobe epilepsy, contributing to lateralization and detecting bilateral abnormalities, which was seen in more than $40 \%$ of the cases. Note that this study was performed at a TE of $135 \mathrm{~ms}$, capable of observing only NAA, Cr, and Cho. The observation of reduced NAA and increased Cho has been replicated in numerous studies and by numerous groups. Moreover, at short TE, there is a consensus that there are increases in $\mathrm{mI}$ observed in the eliptogenic foci. ${ }^{182}$

Several studies have found correlations between MRS alterations and the severity of disease. Hammen et al. ${ }^{183}$ found a negative correlation between the frequency of interictal epileptiform discharges on EEG and NAA levels, and a positive correlation between the duration of seizure symptoms and $\mathrm{Cr}$ levels (at $1.5 \mathrm{~T}$ ). These authors pointed out that, although the intrasubject variations in the NAA and Cr levels were too large to make confident evaluations on individual patients, there were prospects that further technical optimizations (i.e., higher field strength and improved spectral analysis) could make these evaluations possible.

Three earlier studies reported similar kinds of results. Garcia et al. ${ }^{184}$ found that the level of NAA decreased with increased frequency of seizure in patients with temporal lobe or frontal lobe epilepsy. Serles et al. ${ }^{185}$ found an inverse correlation between the frequency of spikes and the NAA/Cr ratio that approached statistical significance in patients with frontal lobe or temporal lobe epilepsy. Park et al. ${ }^{186}$ found an inverse correlation between the NAA/Cr ratio and interictal epileptiform discharges in the contralateral focus of seizure, but not the ipsilateral focus. All of these studies indicate that there could be a role for MRS in evaluating the severity of epilepsy in individual patients.

Recently, several groups have addressed the potential for using MRS in preoperative studies for determining the laterality of the seizure focus (for a detailed metaanalysis of the literature from 1992-2003, see Willmann et al. $\left.{ }^{187}\right)$. Historically, this has been the goal of many MRS studies of epilepsy. The development of established MRI protocols to visualize hippocampal alterations in epilepsy as a basis for identifying seizure focus has helped define three potential clinical uses for the combined MRI/MRS. First, the spectral alterations seen on MRS can be used to confirm the morphological changes seen on MRI. Second, in patients who show no obvious changes on MRI ( $\sim 30 \%$ of patients with temporal lobe epilepsy), MRS can identify the affected hemisphere in a majority of cases based on reductions in NAA and elevations in Cho (see recent results obtained at $1.5 \mathrm{~T}$ with a standard head coil, ${ }^{188}$ and meta-analysis of the literature ${ }^{187}$ ). Third, MRS can be used to predict good surgical outcomes, ${ }^{187}$ because patients with an ipsilateral abnormality have a much better chance of a seizure-free outcome than patients with bilateral abnormalities.

Many of the studies have comments suggesting that the clinical efficacy of MRS will improve at higher fields and with multichannel receiver coils. Also, as was pointed out for $\mathrm{AD}$, many of the results discussed here were made on the basis of the analysis of single-peak ratios or concentrations. Because the MRS abnormalities observed reflect alterations in multiple resonances (NAA, Cho, and others), more definitive statistical comparisons could result from applying approaches such as linear discriminant analysis or $z$-score analysis to take all of these changes into account.

\section{Brain tumors}

The use of proton MRS to study adult brain tumors has been reviewed in the literature. ${ }^{101-103}$ The characteristic spectral features of brain tumors are elevations in Cho, elevations in lipid and lactate in necrotic regions, and reductions in NAA. Hollingworth et al. ${ }^{189}$ recently reported the results of a systematic review of MRS for the characterization of brain tumors. This study examined the role of proton MRS in addressing five clinical questions: 1) distinguishing metastatic lesions from highgrade tumor; 2) high-grade versus low-grade tumor; 3) recurrent tumor versus radiation necrosis; 4) extent of tumor and, 5) tumor versus non-neoplastic lesions. The meta-analysis found that MRS could distinguish between high-grade and low-grade tumors (question 2). There is also a strong indication that MRS (in the context of an integrated MRI/MRS examination) can help in characterizing indeterminate brain lesions (question 5). MRS also shows promise in identifying the extent of tumor (question 4) and distinguishing recurrent tumor from radiation necrosis (question 3 ). The authors strongly suggested using standardized multisite trials to provide more widespread evidence for the use of MRS in addressing questions 3-5.

Besides assessing the efficacy of MRS in addressing these five questions, Hollingworth et al. ${ }^{189}$ made eight recommendations about how future studies should be conducted and evaluated. One recommendation was that MRS studies should be evaluated either in terms of their incremental diagnostic value over standard-of-care MRI or on the basis of the overall diagnostic accuracy of the combination of MRI and MRS. The authors suggested that the article by Moller-Hartmann et al. ${ }^{190}$ provides a good example to follow. They also recommended that, in addition to diagnostic accuracy, MRS should be evaluated in terms of its diagnostic impact. This point has been made for many other diagnostic tests where outcome studies are recommended, in addition to the more tradi- 
tional diagnostic accuracy paradigms. Finally, the costeffectiveness of MRS should be addressed, because this metric is of importance to health care providers and policy makers.

\section{SUMMARY AND FUTURE DIRECTIONS}

Proton MRS can detect a number of compounds that provide biochemical insight about the underlying metabolic basis for many diseases in the brain. Over the past two decades, a great deal of technical progress has been made in acquiring high-quality proton spectra of the brain. Over the past decade, the techniques for acquiring localized spectra have improved substantially.

There have been major improvements in extending MRS from single-voxel methods to multivoxel approaches. Most of the multivoxel methods are slice-selective 2D methods. Generalizing these methods to 3D whole-brain methods involves long acquisition times, which can be prone to artifacts. There are high-speed MRS imaging methods based on either echo-planar methods ${ }^{191,192}$ or spiral acquisitions. ${ }^{193}$ These methods are capable of acquiring spectral data in relatively short scan times, but are usually acquired at relatively high bandwidths, which may limit their signal-to-noise ratios. The use of these methods at higher field strengths (e.g., $3 \mathrm{~T}$ or $4 \mathrm{~T}$ ), with multicoil arrays, or in a combination of both may overcome some of these deficiencies.

Progress has also been made in providing computerbased methods for analyzing these spectra. One result of this progress has been the determination of the reproducibility of MRS in normal controls across various brain regions, localization methods, and field strengths. Another result has been the emergence of meta-analysis of the efficacy of MRS in several pathologies (some of which have been discussed here). As a result, it is now possible to begin to define clinical areas where MRS has proven diagnostic efficacy and to define other promising areas of MRS in which multisite clinical trials could be initiated.

In spite of the technical progress, there are still gaps in the understanding of the biochemistry of each of the compounds detected in the spectra. For example, the precise function of NAA is not completely understood, as is evidenced by the debates about its role as a neuronal marker. Also, the roles of the cholines and $\mathrm{mI}$ in the brain need further investigations. Defining the biochemical roles for all of these compounds could be fruitful areas of research in the future.

Although several groups have examined the levels of Glu, Gln, and GABA, these approaches have not gained much traction in the community. This situation may change with the increasing availability of high-field scanners (3-7 T) and the development of localized multispectral dimensional MRS methods, such as 2D-
COSY. ${ }^{194-196}$ These methods are particularly useful for identifying and detecting spin-coupled resonances such as Glu, Gln, and GABA. Although they require rather long acquisitions in their conventional implementations, recent advances in high-speed methods may make these techniques practical for application in humans. ${ }^{197-202}$

Although the focus here has been on proton MRS methods, several recent advances may make ${ }^{13} \mathrm{C}$ MRS feasible for human studies. These all center around the concept of ${ }^{13} \mathrm{C}$ hyperpolarization, which has been pioneered by the group headed by Golman. ${ }^{203-209}$ Using these techniques, signal-to-noise ratio enhancements of more than 10,000:1 have been achieved in vitro. Historically, many metabolic pathways have been probed using either ${ }^{14} \mathrm{C}$ or (more recently) ${ }^{11} \mathrm{C}$ as radiolabels. It has also been shown that ${ }^{13} \mathrm{C}$ MRS studies using enriched ${ }^{13} \mathrm{C}$ have enormous potential for probing metabolic pathways. The advantages of ${ }^{13} \mathrm{C}$ methods lie in the fact that MR methods can detect the metabolic products of the administered labeled compound, whereas radiotracer studies follow only the tracer. A main disadvantage is the poor signal-to-noise ratio of the method, even at $100 \%$ enrichment. Hyperpolarization, however, may overcome this disadvantage.

In summary, over the past two decades proton MRS of the brain has benefited from technical improvements. Standardization in both spectral acquisitions and their analysis has occurred, primarily in single-voxel methods but also, more slowly, in multivoxel approaches. The availability of higher field scanners and multicoils will both accelerate MRS applications and increase the need for further assessment, validation, and standardization. There are several areas where proton MRS has already proven diagnostic efficacy. The number of these can be expected to only increase over time. One of the next major challenges will be to understand how to extract the maximum amount of clinically useful information from MRS spectra and how to optimally make use of this information, often in combination with other MR-based methods, to affect patient management.

\section{REFERENCES}

1. Burt CT, Cohen SM, Barany M. Analysis of intact tissue with ${ }^{31} \mathrm{P}$ MR. Annu Rev Biophys Bioeng 1979;8:1-25.

2. Burt CT, Wyrwicz AM. Phosphorus-31 nuclear magnetic-resonance observations in biological-systems I. Intact tissue. Trends Biochem Sci 1979;4:244-246.

3. Kuchel PW. Nuclear magnetic-resonance of biological samples. CRC Crit Rev Anal Chem 1981;12:155-231.

4. Roberts JKM, Jardetzky O. Monitoring of cellular-metabolism by NMR. Biochim Biophys Acta 1981;639:53-76.

5. Gadian DG, Radda GK. NMR studies of tissue metabolism. Annu Rev Biochem 1981;50:69-83.

6. Iles RA, Stevens AN, Griffiths JR. NMR studies of metabolites in living tissue. Prog NMR Spectrosc 1982;15:49-200.

7. Bernard M, Canioni P, Cozzone PJ. Study of in vivo cellular metabolism by phosphorus 31 nuclear magnetic resonance [In French]. Biochimie 1983;65:449-470. 
8. Radda GK, Taylor DJ. Applications of nuclear magnetic-resonance spectroscopy in pathology. Int Rev Exp Pathol 1985;27: $1-58$.

9. Avison MJ, Hetherington HP, Shulman RG. Applications of NMR to studies of tissue metabolism. Annu Rev Biophys Biophys Chem 1986;15:377-402.

10. Bottomley PA. Human in vivo NMR spectroscopy in diagnostic medicine: clinical tool or research probe? Radiology 1989;170: $1-15$.

11. Cerdan S, Seelig J. NMR studies of metabolism. Annu Rev Biophys Biophys Chem 1990;19:43-67.

12. Allen PS. In vivo nuclear magnetic resonance spectroscopy applied to medicine. Can Assoc Radiol J 1990;41:39-44.

13. Ruizcabello J, Cohen JS. NMR and the study of pathological state in cells and tissues. Int Rev Cytol 1993;145:1-63.

14. Bottomley PA, Edelstein WA, Foster TH, Adams WA. In vivo solvent-suppressed localized hydrogen nuclear magnetic resonance spectroscopy: a window to metabolism? Proc Natl Acad Sci U S A 1985;82:2148-2152.

15. Frahm J, Bruhn H, Gyngell ML, Merboldt KD, Hanicke W, Sauter R. Localized proton NMR spectroscopy in different regions of the human brain in vivo: relaxation times and concentrations of cerebral metabolites. Magn Reson Med 1989;11: $47-63$.

16. Frahm J, Michaelis T, Merboldt KD, et al. Localized NMR spectroscopy in vivo: progress and problems. NMR Biomed 1989;2: $188-195$.

17. Behar KL, den Hollander JA, Stromski ME, et al. High-resolution ${ }^{1} \mathrm{H}$ nuclear magnetic resonance study of cerebral hypoxia in vivo. Proc Natl Acad Sci U S A 1983;80:4945-4948.

18. Luyten PR, den Hollander JA. Observation of metabolites in the human brain by MR spectroscopy. Radiology 1986;161:795-798.

19. Hanstock CC, Rothman DL, Prichard JW, Jue T, Shulman RG. Spatially localized ${ }^{1} \mathrm{H}$ NMR spectra of metabolites in the human brain. Proc Natl Acad Sci U S A 1988;85:1821-1825.

20. Frahm J, Bruhn H, Gyngell ML, Merboldt KD, Hanicke W, Sauter R. Localized high-resolution proton NMR spectroscopy using stimulated echoes: initial applications to human brain in vivo. Magn Reson Med 1989;9:79-93.

21. Bolinger L, Lenkinski RE. Localization in clinical NMR spectroscopy. In Berliner LJ, Reuben J, editors. Biological magnetic resonance. New York: Plenum Press, 1992:1-53.

22. Aue WP. Localization methods for in vivo nuclear magnetic resonance spectroscopy. Rev Magn Reson Med 1986;1:21-72.

23. Narayana PA, DeLayre JL. Localization methods in NMR. In: Partain CL, Price RR, Patton JA, Kulkarni MV, James AE, editors. Magnetic resonance imaging. $2^{\text {nd }} \mathrm{ed}$, Vol 11. Physical principles and instrumentation. Philadelphia: W.B. Saunders, 1988: 1609-1630.

24. Keevil SF. Spatial localization in nuclear magnetic resonance spectroscopy. Phys Med Biol 2006;51:R579-R636.

25. Gillard JH, Waldman AD, Barker PB, editors. Clinical neuroimaging: diffusion, perfusion and spectroscopy. New York: Cambridge University Press, 2005.

26. Barker PB, Lin DDM. In vivo proton MR spectroscopy of the human brain. Prog NMR Spectrosc 2006;49:99-128.

27. Lentz MR, Taylor JL, Feldman DA, Cheng LL. Current clinical applications of in vivo magnetic resonance spectroscopy and spectroscopic imaging. Curr Med Imaging Rev 2005;1:271-301.

28. Ross BD, Coletti P, Lin A. Magnetic resonance spectroscopy of the brain: neurospectroscopy. In Edelman RR, Hesselink JR, Zlatkin MB, Crues JV, editors. Clinical magnetic resonance imaging, 3rd ed. Philadelphia: Saunders, 2006:1840-1901.

29. Moonen CT, von Kienlin M, van Zijl PC, et al. Comparison of single-shot localization methods (STEAM and PRESS) for in vivo proton NMR spectroscopy. NMR Biomed 1989;2:201-208.

30. Yongbi NM, Payne GS, Collins DJ, Leach MO. Quantification of signal selection efficiency, extra volume suppression and contamination for ISIS, STEAM and PRESS localized ${ }^{1} \mathrm{H}$ NMR spectroscopy using an EEC localization test object. Phys Med Biol 1995;40:1293-1303.

31. Shinnar M, Leigh JS. The application of spinors to pulse synthesis and analysis. Magn Reson Med 1989;12:93-98.
32. Shinnar M, Bolinger L, Leigh JS. The synthesis of soft pulses with a specified frequency response. Magn Reson Med 1989;12: 88-92.

33. Shinnar M, Bolinger L, Leigh JS. The use of finite impulse response filters in pulse design. Magn Reson Med 1989;12: 81-87.

34. Shinnar M, Eleff S, Subramanian H, Leigh JS. The synthesis of pulse sequences yielding arbitrary magnetization vectors. Magn Reson Med 1989;12:74-80.

35. Spielman D, Pauly J, Macovski A, Enzmann D. Spectroscopic imaging with multidimensional pulses for excitation: SIMPLE. Magn Reson Med 1991;19:67-84.

36. Pauly J, Leroux P, Nishimura D, Macovski A. Parameter relations for the Shinnar-Leroux selective excitation pulse design algorithm. IEEE Trans Med Imaging 1991;10:53-65.

37. Chan F, Pauly J, Macovski A. Effects of RF amplifier distortion on selective excitation and their correction by prewarping. Magn Reson Med 1992;23:224-238.

38. Conolly S, Pauly J, Nishimura D, Macovski A. Two-dimensional selective adiabatic pulses. Magn Reson Med 1992;24:302-313.

39. Shinnar M. Reduced power selective excitation radio frequency pulses. Magn Reson Med 1994;32:658-660.

40. Tran TKC, Vigneron DB, Sailasuta N, et al. Very selective suppression pulses for clinical MRSI studies of brain and prostate cancer. Magn Reson Med 2000;43:23-33.

41. Gonen O, Murdoch JB, Stoyanova R, Goelman G. 3D multivoxel proton spectroscopy of human brain using a hybrid of 8th-order Hadamard encoding with 2D chemical shift imaging. Magn Reson Med 1998;39:34-40.

42. Gonen O, Catalaa I, Babb JS, et al. Total brain $N$-acetylaspartate: a new measure of disease load in MS. Neurology 2000;54:15-19.

43. Pohmann R, von Kienlin M, Haase A. Theoretical evaluation and comparison of fast chemical shift imaging methods. J Magn Reson 1997;129:145-160.

44. Brown MA. Time-domain combination of MR spectroscopy data acquired using phased-array coils. Magn Reson Med 2004;52: 1207-1213.

45. Maril N, Lenkinski RE. An automated algorithm for combining multivoxel MRS data acquired with phased-array coils. J Magn Reson Imaging 2005;21:317-322.

46. Roemer PB, Edelstein WA, Hayes CE, Souza SP, Mueller OM. The NMR phased array. Magn Reson Med 1990;16:192-225.

47. Ross B, Bluml S. Magnetic resonance spectroscopy of the human brain. Anat Rec 2001;265:54-84.

48. Lopez Villegas D, Lenkinski RE, Wehrli SL, Ho WZ, Douglas SD. Lactate production by human monocytes macrophages determined by proton MR spectroscopy. Magn Reson Med 1995; 34:32-38.

49. Tallan HH, Moore S, Stein WH. N-Acetyl-L-aspartic acid in brain. J Biol Chem 1956;219:257-264.

50. Birken DL, Oldendorf WH. $N$-Acetyl-L-aspartic acid: a literaturereview of a compound prominent in ${ }^{1} \mathrm{H}-\mathrm{NMR}$ spectroscopic studies of brain. Neurosci Biobehav Rev 1989;13:23-31.

51. Simmons ML, Frondoza CG, Coyle JT. Immunocytochemical localization of $N$-acetyl-aspartate with monoclonal antibodies. Neuroscience 1991;45:37-45.

52. Martin E, Capone A, Schneider J, Hennig J, Thiel T. Absence of $N$-acetylaspartate in the human brain: impact on neurospectroscopy? Ann Neurol 2001;49:518-521.

53. Sullivan EV, Adalsteinsson E, Spielman DM, Hurd RE, Pfefferbaum A. $N$-Acetylaspartate: a marker of neuronal integrity. Ann Neurol 2001;50:823-823.

54. Barker PB. N-Acetyl aspartate: a neuronal marker? Ann Neurol 2001;49:423-424.

55. Martin E, Thiel T, Capone A, Henning J, Schneider J. N-Acetylaspartate: usefulness as an indicator of viable neuronal tissueReply. Ann Neurol 2001;50:824-825.

56. Baslow $\mathrm{MH}$. Brain $N$-acetylaspartate as a molecular water pump and its role in the etiology of Canavan disease: a mechanistic explanation. Mol Neurosci 2003;21:185-189.

57. Baslow MH. $N$-Acetylaspartate in the vertebrate brain: metabolism and function. Neurochem Res 2003;28:941-953. 
58. Baslow MH. Evidence supporting a role for $N$-acetyl-L-aspartate as a molecular water pump in myelinated neurons in the central nervous system: an analytical review. Neurochem Int 2002;40: 295-300.

59. Bluml S, McComb JG, Ross BD. Differentiation between cortical atrophy and hydrocephalus using ${ }^{1} \mathrm{H}$ MRS. Magn Reson Med 1997;37:395-403.

60. Mason GF, Pan JW, Ponder SL, Twieg DB, Pohost GM, Hetherington HP. Detection of brain glutamate and glutamine in spectroscopic images at 4.1 T. Magn Reson Med 1994;32:142-145.

61. JW, Pan Mason GF, Pohost GM, Hetherington HP. Spectroscopic imaging of human brain glutamate by water-suppressed J-refocused coherence transfer at 4.1 T. Magn Reson Med 1996;36:7-12.

62. Ugurbil K, Adriany G, Andersen P, et al. Ultrahigh field magnetic resonance imaging and spectroscopy. Magn Reson Imaging 2003; 21:1263-1281.

63. Tkac I, Rao R, Georgieff MK, Gruetter R. Developmental and regional changes in the neurochemical profile of the rat brain determined by in vivo ${ }^{1} \mathrm{H}$ NMR spectroscopy. Magn Reson Med 2003;50:24-32.

64. Srinivasan R, Cunningham C, Chen A, et al. TE-averaged twodimensional proton spectroscopic imaging of glutamate at $3 \mathrm{~T}$. Neuroimage 2006;30:1171-1178.

65. Sibson NR, Dhankhar A, Mason GF, Rothman DL, Behar KL, Shulman RG. Stoichiometric coupling of brain glucose metabolism and glutamatergic neuronal activity. Proc Natl Acad Sci U S A 1998;95:316-321.

66. Magistretti PJ, Pellerin L, Rothman DL, Shulman RG. Energy on demand. Science 1999;283:496-497.

67. Srinivasan R, Sailasuta N, Hurd R, Nelson S, Pelletier D. Evidence of elevated glutamate in multiple sclerosis using magnetic resonance spectroscopy at $3 \mathrm{~T}$. Brain 2005;128:1016-1025.

68. Ross BD, Jacobson S, Villamil F, et al. Subclinical hepatic encephalopathy: proton MR spectroscopic abnormalities. Radiology 1994;193:457-463.

69. Shawcross DL, Balata S, Damink S, et al. Low myo-inositol and high glutamine levels in brain are associated with neuropsychological deterioration after induced hyperammonemia. Am J Physiol Gastrointest Liver Physiol 2004;287:G503-G509.

70. Mechtcheriakov S, Schocke M, Kugener A, et al. Chemical shift magnetic resonance spectroscopy of cingulate grey matter in patients with minimal hepatic encephalopathy. Neuroradiology 2005;47:27-34.

71. Kreis R, Pfenninger J, Herschkowitz N, Boesch C. In vivo proton magnetic resonance spectroscopy in a case of Reye's syndrome. Intensive Care Med 1995;21:266-269.

72. Moore CM, Wardrop M, Frederick BD, Renshaw PF. Topiramate raises anterior cingulate cortex glutamine levels in healthy men; a 4.0 T magnetic resonance spectroscopy study. Psychopharmacology 2006;188:236-243.

73. Keltner JR, Wald LL, Christensen JD, et al. A technique for detecting GABA in the human brain with PRESS localization and optimized refocusing spectral editing radiofrequency pulses. Magn Reson Med 1996;36:458-461.

74. Keltner JR, Wald LL, Frederick BD, Renshaw PF. In vivo detection of GABA in human brain using a localized double-quantum filter technique. Magn Reson Med 1997;37:366-371.

75. Hetherington HP, Newcomer BR, Pan JW. Measurements of human cerebral GABA at $4.1 \mathrm{~T}$ using numerically optimized editing pulses. Magn Reson Med 1998;39:6-10.

76. Kuzniecky R, Hetherington H, Ho S, et al. Topiramate increases cerebral GABA in healthy humans. Neurology 1998;51:627-629.

77. Ke Y, Cohen BM, Bang JY, Yang MQ, Renshaw PF. Assessment of GABA concentration in human brain using two-dimensional proton magnetic resonance spectroscopy. Psychiatry Res 2000; 100:169-178.

78. Kuzniecky R, Ho S, Pan J, et al. Modulation of cerebral GABA by topiramate, lamotrigine, and gabapentin in healthy adults. Neurology 2002;58:368-372.

79. Ke Y, Streeter CC, Nassar LE, et al. Frontal lobe GABA levels in cocaine dependence: a two-dimensional, J-resolved magnetic resonance spectroscopy study. Psychiatry Res 2004;130:283-293.
80. Jensen JE, Frederick BD, Renshaw PF. Grey and white matter GABA level differences in the human brain using two-dimensional, J-resolved spectroscopic imaging. NMR Biomed 2005;18: 570-576.

81. Jensen JE, Frederick BD, Wang LQ, Brown J, Renshaw PF. Two-dimensional, J-resolved spectroscopic imaging of GABA at 4 tesla in the human brain. Magn Reson Med 2005;54:783-788.

82. Streeter CC, Hennen J, Ke Y, et al. Prefrontal GABA levels in cocaine-dependent subjects increase with pramipexole and venlafaxine treatment. Psychopharmacology 2005;182:516-526.

83. Ross BD, Bluml S. New aspects of brain physiology. NMR Biomed 1996;9:279-296.

84. Hanefeld F, Holzbach U, Kruse B, Wilichowski E, Christen HJ, Frahm J. Diffuse white matter disease in three children: an encephalopathy with unique features on magnetic resonance imaging and proton magnetic resonance spectroscopy. Neuropediatrics 1993;24:244-248.

85. Miller BL. A review of chemical issues in ${ }^{1} \mathrm{H}$ NMR spectroscopy: $N$-acetyl-L-aspartate, creatine and choline. NMR Biomed 1991;4: 47-52.

86. Gill SS, Small RK, Thomas DG, et al. Brain metabolites as ${ }^{1} \mathrm{H}$ NMR markers of neuronal and glial disorders. NMR Biomed 1989;2:196-200.

87. Gill SS, Thomas DG, Van Bruggen N, et al. Proton MR spectroscopy of intracranial tumours: in vivo and in vitro studies. J Comput Assist Tomogr 1990;14:497-504.

88. Kotitschke K, Jung H, Nekolla S, Haase A, Bauer A, Bogdahn U. High-resolution one- and two-dimensional ${ }^{1} \mathrm{H}$ MRS of human brain tumor and normal glial cells. NMR Biomed 1994;7:111120.

89. Matthews PM, Francis G, Antel J, Arnold DL. Proton magnetic resonance spectroscopy for metabolic characterization of plaques in multiple sclerosis. Neurology 1991;41:1251-1256.

90. Venkatesh SK, Gupta RK, Pal L, Husain N, Husain M. Spectroscopic increase in choline signal is a nonspecific marker for differentiation of infective/inflammatory from neoplastic lesions of the brain. J Magn Reson Imaging 2001;14:8-15.

91. Brenner RE, Munro PM, Williams SC, et al. The proton NMR spectrum in acute EAE: the significance of the change in the Cho:Cr ratio. Magn Reson Med 1993;29:737-745.

92. Butteriss DJA, Ismail A, Ellison DW, Birchall D. Use of serial proton magnetic resonance spectroscopy to differentiate low grade glioma from tumefactive plaque in a patient with multiple sclerosis. Br J Radiol 2003;76:662-665.

93. Law M, Meltzer DE, Cha S. Spectroscopic magnetic resonance imaging of a tumefactive demyelinating lesion. Neuroradiology 2002;44:986-989.

94. Saindane AM, Cha S, Law M, Xue X, Knopp EA, Zagzag D. Proton MR Spectroscopy of tumefactive demyelinating lesions. Am J Neuroradiol 2002;23:1378-1386.

95. Ernst T, Chang L, Walot I, Huff K. Physiologic MRI of a tumefactive multiple sclerosis lesion. Neurology 1998;51:1486-1488.

96. Negendank W. Studies of human tumors by MRS: a review. NMR Biomed 1992;5:303-324.

97. Aboagye EO, Bhujwalla ZM. Malignant transformation alters membrane choline phospholipid metabolism of human mammary epithelial cells. Cancer Res 1999;59:80-84.

98. Podo F. Tumour phospholipid metabolism. NMR Biomed 1999; 12:413-439.

99. Kwock L, Smith JK, Castillo M, et al. Clinical applications of proton MR spectroscopy in oncology. Technol Cancer Res Treat 2002;1:17-28.

100. Smith JK, Castillo M, Kwock L. MR spectroscopy of brain tumors. Magn Reson Imaging Clin N Am 2003;11:415-429, v-vi.

101. Nelson SJ. Magnetic resonance spectroscopic imaging. Evaluating responses to therapy for gliomas. IEEE Eng Med Biol Mag 2004;23:30-39.

102. Alger JR. MR Spectroscopy of brain tumors in adults. In Gillard JH, Waldman AD, Barker PB, editors. Clinical MR neuroimaging: diffusion, perfusion and spectroscopy. New York: Cambridge University Press, 2005:288-311.

103. Kwock L, Smith JK, Castillo M, et al. Clinical role of proton 
magnetic resonance spectroscopy in oncology: brain, breast, and prostate cancer. Lancet Oncol 2006;7:859-868.

104. Font C, García-Campos M, Hansen AJ, Siemkowicz E, Gjedde A. Simultaneous diffusion of inositol and mannitol in the rat brain [In Spanish]. Rev Esp Fisiol 1982;38:317-319.

105. Brand A, Richter-Landsberg C, Leibfritz D. Multinuclear NMR studies on the energy metabolism of glial and neuronal cells. Dev Neurosci 1993;15:289-298.

106. Strange K, Emma F, Paredes A, Morrison R. Osmoregulatory changes in myo-inositol content and $\mathrm{Na}+$ /myo-inositol cotransport in rat cortical astrocytes. Glia 1994;12:35-43.

107. Kruse B, Hanefeld F, Christen HJ, et al. Alterations of brain metabolites in metachromatic leukodystrophy as detected by localized proton magnetic resonance spectroscopy in vivo. J Neurol 1993;241:68-74.

108. Jansen JF, Backes WH, Nicolay K, Kooi ME. 1H MR spectroscopy of the brain: absolute quantification of metabolites. Radiology 2006;240:318-332.

109. Hennig J, Pfister H, Ernst T, Ott D. Direct absolute quantification of metabolites in the human brain with invivolLocalized proton spectroscopy. NMR Biomed 1992;5:193-199.

110. Kreis R, Ernst T, Ross BD. Absolute quantitation of water and metabolites in the human brain. 2. Metabolite concentrations. J Cardiovasc Magn Reson Ser B 1993;102:9-19.

111. Ernst T, Kreis R, Ross BD. Absolute quantitation of water and metabolites in the human brain. 1. Compartments and water. J Cardiovasc Magn Reson Ser B 1993;102:1-8.

112. Kreis R, Ernst T, Ross BD. Development of the human brain: in vivo quantification of metabolite and water content with proton magnetic resonance spectroscopy. Magn Reson Med 1993;30: 424-437.

113. Helms G. A precise and user-independent quantification technique for regional comparison of single volume proton MR spectroscopy of the human brain. NMR Biomed 2000;13:398-406.

114. Helms G. Volume correction for edema in single-volume proton MR spectroscopy of contrast-enhancing multiple sclerosis lesions. Magn Reson Med 2001;46:256-263.

115. Knight-Scott J, Haley AP, Rossmiller SR, et al. Molality as a unit of measure for expressing ${ }^{1} \mathrm{H}$ MRS brain metabolite concentrations in vivo. Magn Reson Imaging 2003;21:787-797.

116. Horska A, Calhoun VD, Bradshaw DH, Barker PB. Rapid method for correction of CSF partial volume in quantitative proton MR spectroscopic imaging. Magn Reson Med 2002;48:555-558.

117. Zandt $H$, van der Graaf M, Heerschap A. Common processing of in vivo MR spectra. NMR Biomed 2001;14:224-232.

118. Vanhamme L, Sundin T, Van Hecke P, Van Huffel S. MR spectroscopy quantitation: a review of time-domain methods. NMR Biomed 2001;14:233-246.

119. Mierisova S, Ala-Korpela M. MR spectroscopy quantitation: a review of frequency domain methods. NMR Biomed 2001;14: 247-259.

120. Provencher SW. Automatic quantitation of localized in vivo ${ }^{1} \mathrm{H}$ spectra with LCModel. NMR Biomed 2001;14:260-264.

121. McLean MA, Woermann FG, Simister RJ, Barker GJ, Duncan JS. In vivo short echo time ${ }^{1} \mathrm{H}$-magnetic resonance spectroscopic imaging (MRSI) of the temporal lobes. Neuroimage 2001;14: 501-509.

122. McLean MA, Woermann FG, Barker GJ, Duncan JS. Quantitative analysis of short echo time ${ }^{1} \mathrm{H}$-MRSI of cerebral gray and white matter. Magn Reson Med 2000;44:401-411.

123. Webb PG, Sailasuta N, Kohler SJ, Raidy T, Moats RA, Hurd RE. Automated single-voxel proton MRS: technical development and multisite verification. Magn Reson Med 1994;31:365-373.

124. Venkatraman TN, Hamer RM, Perkins DO, Song AW, Lieberman JA, Steen RG. Single-voxel ${ }^{1} \mathrm{H}$ PRESS at $4.0 \mathrm{~T}$ : precision and variability of measurements in anterior cingulate and hippocampus. NMR Biomed 2006;19:484-491.

125. Macri MA, Garreffa $G$, Giove $F$, et al. In vivo quantitative ${ }^{1} \mathrm{H}$ MRS of cerebellum and evaluation of quantitation reproducibility by simulation of different levels of noise and spectral resolution. Magn Reson Imaging 2004;22:1385-1393.

126. Kubo H, Harada M, Sakama M, Nishitani H. Reproducibility of metabolite concentration evaluated by intraclass correlation co- efficient using clinical MR apparatus. J Comput Assist Tomogr 2003;27:449-453.

127. Hsu YY, Chen MC, Lim KE, Chang C. Reproducibility of hippocampal single-voxel proton MR spectroscopy and chemical shift imaging. AJR Am J Roentgenol 2001;176:529-536.

128. Bartha R, Drost DJ, Menon RS, Williamson PC. Comparison of the quantification precision of human short echo time $\mathrm{H} 1$ spectroscopy at 1.5 and 4.0 tesla. Magn Reson Med 2000;44:185-192.

129. Schirmer T, Auer DP. On the reliability of quantitative clinical magnetic resonance spectroscopy of the human brain. NMR Biomed 2000;13:28-36.

130. Simmons A, Smail M, Moore E, Williams SCR. Serial precision of metabolite peak area ratios and water referenced metabolite peak areas in proton MR spectroscopy of the human brain. Magn Reson Imaging 1998;16:319-330.

131. Stanley JA, Drost DJ, Williamson PC, Thompson RT. The use of a priori knowledge to quantify short echo in vivo ${ }^{1} \mathrm{H}$ MR spectra. Magn Reson Med 1995;34:17-24.

132. Provencher SW. Estimation of metabolite concentrations from localized in vivo proton NMR spectra. Magn Reson Med 1993; 30:672-679.

133. Narayana PA, Johnston D, Flamig DP. In vivo proton magnetic resonance spectroscopy studies of human brain. Magn Reson Imaging 1991;9:303-308.

134. Christiansen P, Henriksen O, Stubgaard M, Gideon P, Larsson HB. In vivo quantification of brain metabolites by ${ }^{1} \mathrm{H}-\mathrm{MRS}$ using water as an internal standard. Magn Reson Imaging 1993;11:107118 .

135. Michaelis T, Merboldt KD, Bruhn H, Hanicke W, Frahm J. Absolute concentrations of metabolites in the adult human brain in vivo: quantification of localized proton MR spectra. Radiology 1993;187:219-227.

136. Danielsen ER, Henriksen O. Absolute quantitative proton NMR spectroscopy based on the amplitude of the local water suppression pulse: quantification of brain water and metabolites. NMR Biomed 1994;7:311-318.

137. Marshall I, Wardlaw J, Cannon J, Slattery J, Sellar RJ. Reproducibility of metabolite peak areas in ${ }^{1} \mathrm{H}$ MRS of brain. Magn Reson Med 1996;14:281-292.

138. Brooks WM, Friedman SD, Stidley CA. Reproducibility of ${ }^{1} \mathrm{H}-$ MRS in vivo. Magn Reson Med 1999;41:193-197.

139. Choi CG, Frahm J. Localized proton MRS of the human hippocampus: metabolite concentrations and relaxation times. Magn Reson Med 1999;41:204-207.

140. Helms G. Analysis of 1.5 tesla proton MR spectra of human brain using LCModel and an imported basis set. Magn Reson Imaging 1999;17:1211-1218.

141. Mullins PG, Rowland L, Bustillo J, Bedrick EJ, Lauriello J, Brooks WM. Reproducibility of ${ }^{1} \mathrm{H}$-MRS measurements in schizophrenic patients. Magn Reson Med 2003;50:704-707.

142. Sigmundsson T, Maier M, Toone BK, et al. Frontal lobe $N$ acetylaspartate correlates with psychopathology in schizophrenia: a proton magnetic resonance spectroscopy study. Schizophr Res 2003;64:63-71.

143. Geurts JJG, Barkhof F, Castelijns JA, Uitdehaag BMJ, Polman $\mathrm{CH}$, Pouwels PJW. Quantitative ${ }^{1} \mathrm{H}-\mathrm{MRS}$ of healthy human cortex, hippocampus, and thalamus: metabolite concentrations, quantification precision, and reproducibility. J Magn Reson Imaging 2004;20:366-371.

144. Komoroski RA, Kotrla KJ, Lemen L, Lindquist D, Diaz P, Foundas A. Brain metabolite concentration ratios in vivo: multisite reproducibility by single-voxel ${ }^{1} \mathrm{H}$ MR spectroscopy. Magn Reson Imaging 2004;22:721-725.

145. Steen RG, Hamer RM, Lieberman JA. Measurement of brain metabolites by ${ }^{1} \mathrm{H}$ magnetic resonance spectroscopy in patients with schizophrenia: a systematic review and meta-analysis. Neuropsychopharmacology 2005;30:1949-1962.

146. Michael N, Gosling M, Reutemann M, et al. Metabolic changes after repetitive transcranial magnetic stimulation (rTMS) of the left prefrontal cortex: a sham-controlled proton magnetic resonance spectroscopy (1H MRS) study of healthy brain. Eur J Neurosci 2003;17:2462-2468.

147. Hammen T, Stadlbauer A, Tomandl B, et al. Short TE single- 
voxel ${ }^{1} \mathrm{H}-\mathrm{MR}$ spectroscopy of hippocampal structures in healthy adults at 1.5 tesla: how reproducible are the results? NMR Biomed 2005;18:195-201.

148. Wellard RM, Briellmann RS, Jennings C, Jackson GD. Physiologic variability of single-voxel proton MR spectroscopic measurements at 3T. AJNR Am J Neuroradiol 2005;26:585-590.

149. Soreni N, Noseworthy MD, Cormier T, Oakden WK, Bells S, Schachar R. Intraindividual variability of striatal (1)H-MRS brain metabolite measurements at 3 T. Magn Reson Imaging 2006;24: 187-194.

150. Jayasundar R, Raghunathan P. Evidence for left-right asymmetries in the proton MRS of brain in normal volunteers. Magn Reson Imaging 1997;15:223-234.

151. Ricci PE, Pitt A, Keller PJ, Coons SW, Heiserman JE. Effect of voxel position on single-voxel MR spectroscopy findings. AJNR Am J Neuroradiol 2000;21:367-374.

152. Jayasundar R. Human brain: biochemical lateralization in normal subjects. Neurol India 2002;50:267-271.

153. Inglese M, Spindler M, Babb JS, Sunenshine P, Law M, Gonen O. Field, coil, and echo-time influence on sensitivity and reproducibility of brain proton MR spectroscopy. AJNR Am J Neuroradiol 2006;27:684-688.

154. Srinivasan R, Vigneron D, Sailasuta N, Hurd R, Nelson S. A comparative study of myo-inositol quantification using LCmodel at $1.5 \mathrm{~T}$ and $3.0 \mathrm{~T}$ with $3 \mathrm{D}{ }^{1} \mathrm{H}$ proton spectroscopic imaging of the human brain. Magn Reson Imaging 2004;22:523-528.

155. Marshall I, Wardlaw J, Graham C, Murray L, Blane A. Repeatability of long and short echo-time in vivo proton chemical-shift imaging. Neuroradiology 2002;44:973-980.

156. Chard DT, McLean MA, Parker GJM, MacManus DG, Miller DH. Reproducibility of in vivo metabolite quantification with proton magnetic resonance spectroscopic imaging. J Magn Reson Imaging 2002;15:219-225.

157. Li BSY, Babb JS, Soher BJ, Maudsley AA, Gonen O. Reproducibility of 3D proton spectroscopy in the human brain. Magn Reson Med 2002;47:439-446.

158. Wiedermann D, Schuff N, Matson GB, et al. Short echo time multislice proton magnetic resonance spectroscopic imaging in human brain: metabolite distributions and reliability. Magn Reson Imaging 2001;19:1073-1080.

159. Maton B, Londono A, Sawrie S, Knowlton R, denHollander J, Kuzniecky R. Reproducibility of proton magnetic resonance spectroscopy imaging measurements of normal human hippocampus at 1.5 T: clinical implications. J Neuroimaging 2001;11:194201.

160. Narayana PA, Doyle TJ, Lai DJ, Wolinsky JS. Serial proton magnetic resonance spectroscopic imaging, contrast-enhanced magnetic resonance imaging, and quantitative lesion volumetry in multiple sclerosis. Ann Neurol 1998;43:56-71.

161. Tedeschi G, Bertolino A, Campbell G, et al. Reproducibility of proton MR spectroscopic imaging findings. AJNR Am J Neuroradiol 1996; 17:1871-1879.

162. Charles HC, Lazeyras F, Tupler LA, Krishnan KRR. Reproducibility of high spatial resolution proton magnetic resonance spectroscopic imaging in the human brains. Magn Reson Med 1996; 35:606-610.

163. Bertolino A, Callicott JH, Nawroz S, et al. Reproducibility of proton magnetic resonance spectroscopic imaging in patients with schizophrenia. Neuropsychopharmacology 1998;18:1-9.

164. Jackson EF, Doyle TJ, Wolinsky JS, Narayana PA. Short TE hydrogen-1 spectroscopic MR imaging of normal human brain: reproducibility studies. J Magn Reson Imaging 1994;4:545-551.

165. Lenkinski RE. High-field magnetic resonance imaging. In: Edelman RR, Hesselink JR, Zlatkin MB, Crues JV 3rd, editors. Clinical magnetic resonance imaging. Philadelphia: Saunders Elsevier, 2006:493-511.

166. Tkac I, Andersen P, Adriany G, Merkle H, Ugurbil K, Gruetter R. In vivo ${ }^{1} \mathrm{H}$ NMR spectroscopy of the human brain at $7 \mathrm{~T}$. Magn Reson Med 2001;46:451-456.

167. Barker PB, Hearshen DO, Boska MD. Single-voxel proton MRS of the human brain at 1.5T and 3.0T. Magn Reson Med 2001;45: 765-769.

168. Gonen O, Gruber S, Li BSY, Mlynarik V, Moser E. Multivoxel
$3 \mathrm{D}$ proton spectroscopy in the brain at 1.5 versus $3.0 \mathrm{~T}$ : signal-to-noise ratio and resolution comparison. AJNR Am J Neuroradiol 2001;22:1727-1731.

169. Li BSY, Regal J, Gonen O. SNR versus resolution in $3 \mathrm{D}{ }^{1} \mathrm{H}$ MRS of the human brain at high magnetic fields. Magn Reson Med 2001;46:1049-1053.

170. Lenkinski RE. MR spectroscopy. In Filippi M, De Stefano N, Dousset V, McGowan JC, editors. MR imaging in white matter diseases of the brain and spinal cord. New York: Springer, 2005: 288-311.

171. Mandal PK. Magnetic resonance spectroscopy (MRS) and its application in Alzheimer disease. concepts in magnetic resonance Part A 2007;30A:40-64.

172. Soher BJ, Doraiswamy PM, Charles HC. A review of ${ }^{1} \mathrm{H}$ MR spectroscopy findings in Alzheimer's disease. Neuroimaging Clin N Am 2005; 15:847-852.

173. Miller BL, Moats RA, Shonk T, Ernst T, Woolley S, Ross BD. Alzheimer disease: depiction of increased cerebral myo-inositol with proton MR spectroscopy. Radiology 1993;187:433-437.

174. Kantarci K, Petersen RC, Boeve BF, et al. 1H MR spectroscopy in common dementias. Neurology 2004;63:1393-1398.

175. den Heijer T, Sijens PE, Prins ND, et al. MR spectroscopy of brain white matter in the prediction of dementia. Neurology 2006; 66:540-544.

176. Metastasio A, Rinaldi P, Tarducci R, et al. Conversion of MCI to dementia: role of proton magnetic resonance spectroscopy. Neurobiol Aging 2006;27:926-932.

177. Kantarci K, Smith GE, Ivnik RJ, et al. 1H Magnetic resonance spectroscopy, cognitive function, and apolipoprotein E genotype in normal aging, mild cognitive impairment and Alzheimer's disease. J Int Neuropsychol Soc 2002;8:934-942.

178. Doraiswamy PM, Charles HC, Krishnan KRR. Prediction of cognitive decline in early Alzheimer's disease. Lancet 1998;352: $1678-1678$

179. Ross AJ, Sachdev PS. Magnetic resonance spectroscopy in cognitive research. Brain Res Rev 2004;44:83-102.

180. Briellmann RS, Wellard RM, Jackson GD. MR Spectroscopy in seizure disorders. In: Gillard JH, Waldman AD, Barker PB, editors. Clinical MR neuroimaging: diffusion, perfusion and spectroscopy. New York: Cambridge University Press, 2005:488508 .

181. Connelly A, Jackson GD, Duncan JS, King MD, Gadian DG. Magnetic resonance spectroscopy in temporal lobe epilepsy. Neurology 1994;44:1411-1417.

182. Wellard RM, Briellmann RS, Prichard JW, Syngeniotis A, Jackson GD. Myoinositol abnormalities in temporal lobe epilepsy. Epilepsia 2003;44:815-821.

183. Hammen T, Schwarz M, Doelken M, et al. 1H-MR spectroscopy indicates severity markers in temporal lobe epilepsy: correlations between metabolic alterations, seizures, and epileptic discharges in EEG. Epilepsia 2007;48:263-269.

184. Garcia PA, Laxer KD, van der Grond J, Hugg JW, Matson GB, Weiner MW. Correlation of seizure frequency with $\mathrm{N}$-acetylaspartate levels determined by ${ }^{1} \mathrm{H}$ magnetic resonance spectroscopic imaging. Magn Reson Imaging 1997;15:475-478.

185. Serles W, Li LM, Caramanos Z, Arnold DL, Gotman J. Relation of interictal spike frequency to ${ }^{1} \mathrm{H}$-MRSI-measured NAA/Cr. Epilepsia 1999;40:1821-1827.

186. Park SA, Kim GS, Lee SK, et al. Interictal epileptiform discharges relate to ${ }^{1} \mathrm{H}$-MRS-detected metabolic abnormalities in mesial temporal lobe epilepsy. Epilepsia 2002;43:1385-1389.

187. Willmann O, Wennberg R, May T, Woermann FG, PohlmannEden B. The role of ${ }^{1} \mathrm{H}$ magnetic resonance spectroscopy in pre-operative evaluation for epilepsy surgery: a meta-analysis. Epilepsy Res 2006;71:149-158.

188. Hammen T, Kerling F, Schwarz M, et al. Identifying the affected hemisphere by ${ }^{1} \mathrm{H}-\mathrm{MR}$ spectroscopy in patients with temporal lobe epilepsy and no pathological findings in high resolution MRI. Eur J Neurol 2006;13:482-490.

189. Hollingworth W, Medina LS, Lenkinski RE, et al. A systematic literature review of magnetic resonance spectroscopy for the characterization of brain tumors. AJNR Am J Neuroradiol 2006;27: $1404-1411$. 
190. Moller-Hartmann W, Herminghaus S, Krings T, et al. Clinical application of proton magnetic resonance spectroscopy in the diagnosis of intracranial mass lesions. Neuroradiology 2002;44: 371-381.

191. Posse S, DeCarli C, Le Bihan D. Three-dimensional echo-planar MR spectroscopic imaging at short echo times in the human brain. Radiology 1994;192:733-738.

192. Posse S, Tedeschi G, Risinger R, Ogg R, Le Bihan D. High speed ${ }^{1} \mathrm{H}$ spectroscopic imaging in human brain by echo planar spatialspectral encoding. Magn Reson Med 1995;33:34-40.

193. Adalsteinsson E, Irarrazabal P, Spielman DM, Macovski A. Three-dimensional spectroscopic imaging with time-varying gradients. Magn Reson Med 1995;33:461-466.

194. Thomas MA, Binesh N, Yue K, DeBruhl N. Volume-localized two-dimensional correlated magnetic resonance spectroscopy of human breast cancer. J Magn Reson Imaging 2001;14: $181-186$.

195. Thomas MA, Ryner LN, Mehta MP, Turski PA, Sorenson JA. Localized 2D J-resolved ${ }^{1} \mathrm{H}$ MR spectroscopy of human brain tumors in vivo. J Magn Reson Imaging 1996;6:453-459.

196. Thomas MA, Yue K, Binesh N, et al. Localized two-dimensional shift correlated MR spectroscopy of human brain. Magn Reson Med 2001;46:58-67.

197. Frydman L, Lupulescu A, Scherf T. Principles and features of single-scan two-dimensional NMR spectroscopy. J Am Chem Soc 2003;125:9204-9217.

198. Mishkovsky M, Frydman L. Interlaced Fourier transformation of ultrafast 2D NMR data. J Magn Reson 2005;173:344-350.

199. Sela N, Degani H, Frydman L. Ultrafast 2D NMR spectroscopy using sinusoidal gradients: principles and ex vivo brain investigations. Magn Reson Med 2004;52:893-897.

200. Shapira B, Frydman L. Spatially encoded pulse sequences for the acquisition of high resolution NMR spectra in inhomogeneous fields. J Magn Reson 2006;182:12-21.

201. Shrot Y, Frydman L. Single-scan NMR spectroscopy at arbitrary dimensions. J Am Chem Soc 2003;125:11385-11396.

202. Shrot Y, Shapira B, Frydman L. Ultrafast 2D NMR spectroscopy using a continuous spatial encoding of the spin interactions. J Magn Reson 2004;171:163-170.

203. Ardenkjaer-Larsen JH, Fridlund B, Gram A, et al. Increase in signal-to-noise ratio of $>10,000$ times in liquid-state NMR. Proc Natl Acad Sci U S A 2003;100:10158-10163.

204. Golman K, Ardenkjaer-Larsen JH, Petersson JS, Mansson S, Leunbach I. Molecular imaging with endogenous substances. Proc Natl Acad Sci U S A 2003;100:10435-10439.

205. Golman K, Zandt RI, Thaning M. Real-time metabolic imaging. Proc Natl Acad Sci U S A 2006;103:11270-11275.

206. Golman K, Olsson LE, Axelsson O, Mansson S, Karlsson M, Petersson JS. Molecular imaging using hyperpolarized ${ }^{13} \mathrm{C} . \mathrm{Br} J$ Radiol 2003;76 Spec No 2:S118-127.

207. Golman K, Petersson JS. Metabolic imaging and other applications of hyperpolarized ${ }^{13} \mathrm{C}$. Acad Radiol 2006;13:932-942.

208. Golman K, Zandt RI, Lerche M, Pehrson R, Ardenkjaer-Larsen JH. Metabolic imaging by hyperpolarized ${ }^{13} \mathrm{C}$ magnetic resonance imaging for in vivo tumor diagnosis. Cancer Res 2006;66:10855-10860.

209. Mansson S, Johansson E, Magnusson P, et al. ${ }^{13} \mathrm{C}$ imaging: a new diagnostic platform. Eur Radiol 2006;16:57-67. 